\title{
A Theoretical Study of the Insertion of Atoms and Ions into Titanosilsequioxane (Ti-POSS) in Comparison with POSS
}

\author{
Yosuke Komagata, Takaaki Iimura, Nobuhiro Shima, and Takako Kudo \\ Department of Chemistry and Chemical Biology, Graduate School of Engineering, Gunma University, \\ 1-5-1 Tenjin-cho, Kiryu 376-8515, Japan \\ Correspondence should be addressed to Takako Kudo, tkudo@gunma-u.ac.jp
}

Received 9 June 2012; Revised 26 August 2012; Accepted 26 August 2012

Academic Editor: Kensuke Naka

Copyright (C) 2012 Yosuke Komagata et al. This is an open access article distributed under the Creative Commons Attribution License, which permits unrestricted use, distribution, and reproduction in any medium, provided the original work is properly cited.

\begin{abstract}
The insertion reaction of various guest species, such as rare gases $(\mathrm{He}, \mathrm{Ne}$, and $\mathrm{Ar})$, cations of group $1\left(\mathrm{Li}^{+}, \mathrm{Na}^{+}\right.$, and $\left.\mathrm{K}^{+}\right)$, and anions of group $17\left(\mathrm{~F}^{-}\right.$and $\left.\mathrm{Cl}^{-}\right)$elements, into the Ti analogues of POSS (polyhedral oligomeric silsesquioxanes), Ti-POSS, $\left[\mathrm{HTiO}_{1.5}\right]_{n}(n=8$ and 10$)$, has been investigated by ab initio molecular orbital and density functional methods. For each case, the properties of the exohedral and endohedral complexes and transition-state structure connecting them on the potential energy surface and energetics are discussed in comparison with the case of POSS. Furthermore, in order to understand the origin of the stability of these structures, the binding energy $\left(\Delta E_{\text {comp }}\right)$ and the energy barrier of the encapsulation are analyzed by an energy decomposition method. As a result, some similarities and differences between Ti-POSS and POSS were explored.
\end{abstract}

\section{Introduction}

Polyhedral oligomeric silsesquioxanes (POSS), $\left[\mathrm{RSiO}_{1.5}\right]_{n}$ $(n=4,6,8,10,12, \ldots)$, referred to as $\mathrm{T}_{n}$, have been the focus of considerable experimental and theoretical interest because of their wide variety of practical uses for many years [1-4]. Among a huge number of investigations for these diverse polyhedral compounds, the approach to make use of their cavity for various purposes, such as a container of atomic or molecular species [5-19], medical supplies [20, 21], molecular sieves, or a reaction filed for $\mathrm{H}_{2}$ formation [22], is one of the extremely attractive research areas of the POSS chemistry. In addition to many interesting experimental observations, theoretical studies have been making considerable contributions in this area. For example, there are systematic and comprehensive studies for the encapsulation of various atomic or ionic species into $\mathrm{T}_{8}$ and $\mathrm{T}_{10}$ by Hossain et al. $[9$, $13,15,16]$. Furthermore, incorporation of molecular species such as $\mathrm{H}_{2}, \mathrm{~N}_{2}$, and $\mathrm{O}_{2}$ inside $\mathrm{T}_{n}(n=6-12)$ that also been investigated by our group $[5,18,19]$. These studies must give useful information for the future design of the molecular sieve or better drug delivery.
On the other hand, metal-substituted POSS (metallasilsesquioxanes) where the skeletal silicon atoms of POSS are all or partially replaced with various metals such as group 4 ( $\mathrm{Ti}, \mathrm{Zr}$, and $\mathrm{Hf}$ ) [23-29] or other heavier group 14 (Ge Sn) [29] elements are also fascinating research targets. The titanosilsequioxanes especially $\left(\mathrm{Ti}-\mathrm{T}_{n}\right)$ have extensively been studied both by experimental and theoretical chemists because of their potential as useful materials such as promising catalysts. For the experimental works, the titaniumsubstituted $\mathrm{T}_{8}$ with the $\mathrm{TiSi}_{7} \mathrm{O}_{12}$ core $[24,26]$ and even the Si/Ti-alternated $\mathrm{T}_{8}$ with the $\mathrm{Ti}_{4} \mathrm{Si}_{4} \mathrm{O}_{12}$ core $[23,25]$ have already been synthesized and their stability or catalytic activity investigated years ago. On the other hand, not for Ti-POSS but some theoretical studies on the structures and catalytic reactions of the model compounds of titanosilicate or titanium-containing zeolites are available $[30,31]$. In the past several years, therefore, we have studied the structures and catalytic ability of the titanium analogues of POSS, $\left[\mathrm{HTiO}_{1.5}\right]_{n}$ and $\mathrm{H}_{8} \mathrm{Ti}_{p} \mathrm{Si}_{8-p} \mathrm{O}_{12}$ [27]. Incidentally, the experimental result [23] for the structure of the Si/Tialternated $\mathrm{T}_{8}$ is in good agreement with our calculational result [27]. Our next target is their various intramolecular 
TABle 1: Some geometrical parameters ( $\AA$ and degrees), the averaged net atomic charge, a energy level of HOMO and LUMO, and the HOMO-LUMO energy gap (hartree) $)^{\mathrm{c}}$ of $\mathrm{Ti}^{-} \mathrm{T}_{8}$ and $\mathrm{Si}-\mathrm{T}_{8}$ at the B3LYP/6-311+G(d) level.

\begin{tabular}{|c|c|c|c|c|c|c|}
\hline A & $\mathrm{A}-\mathrm{O}$ & A-H & $<\mathrm{AOA}$ & $<\mathrm{OAO}$ & $C^{b}-A$ & $\mathrm{C}^{\mathrm{a}-\mathrm{O}}$ \\
\hline Si & 1.644 & 1.460 & 148.4 & 109.2 & 2.744 & 2.690 \\
\hline $\mathrm{Ti}$ & 1.811 & 1.697 & 149.1 & 109.1 & 3.023 & 2.951 \\
\hline A & $q_{\mathrm{A}}^{\mathrm{a}}$ & $q_{\mathrm{o}}{ }^{\mathrm{a}}$ & $\mathrm{HOMO}^{\mathrm{c}}$ & $\mathrm{LUMO}^{\mathrm{c}}$ & $\Delta E_{(\mathrm{H}-\mathrm{L})}^{\mathrm{c}}$ & \\
\hline $\mathrm{Si}$ & $2.131(0.767)$ & $-1.268(-0.474)$ & $-0.319[-0.483]$ & $-0.007[0.052]$ & $0.312[0.535]$ & \\
\hline $\mathrm{Ti}$ & $1.313(0.202)$ & $-0.787(-0.110)$ & $-0.328[-0.464]$ & $-0.139[0.019]$ & $0.189[0.483]$ & \\
\hline
\end{tabular}

${ }^{\mathrm{a}} \mathrm{NBO}$ and Mulliken (in parentheses) net atomic charges on $\mathrm{A}$ ( $\mathrm{Si}$ and $\mathrm{Ti}$ ) and $\mathrm{O}$ atoms.

${ }^{\mathrm{b}} \mathrm{C}$ is the center of the cage.

${ }^{\mathrm{c}}$ The HF/6-311+G(d) values are in square brackets.

reactions. Therefore, in the present study, as a continuation of our theoretical approach for Ti-POSS and to deepen our understanding for POSS, the result of the investigation for the encapsulation of various atoms and ions into Ti$\mathrm{T}_{8}\left(\left[\mathrm{HTiO}_{1.5}\right]_{8}\right)$ is shown and discussed in comparison with the case of the Si analogue, $\mathrm{T}_{8}\left(\left[\mathrm{HSiO}_{1.5}\right]_{8}\right)$.

\section{Computational Methods}

Geometry optimizations were performed for all of the molecules investigated here at the Hartree-Fock (HF) and a hybrid type of the HF and DFT theories, B3LYP [32] levels of theory. For the basis set, 6-311+G(d) [33-35] was finally chosen after the investigation of several kinds of basis sets. We have investigated the effect of six kinds of basis sets $(6-31 G(d), 6-311 G(d), 6-31+G(d), 6-31 G(d, p), 6-$ $31+G(d, p)$, and $6-311+G(d))$ for the geometries of exohedral and endohedral complexes between $\mathrm{X}\left(\mathrm{He}\right.$ and $\left.\mathrm{F}^{-}\right)$and $\mathrm{Ti}-\mathrm{T}_{8}$ at the HF and B3LYP levels of theory. As a result, a set of $\mathrm{p}$ functions on hydrogen atoms is found to have small effect so it was not considered in this study. All optimized geometries were characterized as minima or transition states by normal frequency mode analyses. In addition, single point energy calculations on the optimized geometries were carried out at the second-order perturbation (MP2) [36] level of theory for a part of the system involving $\mathrm{F}^{-}$to obtain more reliable energetics. Finally, the relative energies of the stationary points were corrected by considering the zero point energy (described as “+ZPC”).

Furthermore, in order to explore the origin of the stability of the stationary points on the potential energy surface of the encapsulation reactions in detail, we carried out a kind of energy decomposition for the binding energy $\left(\Delta E_{\text {comp }}\right)$ between the guest species and the host $\mathrm{Ti}^{-} \mathrm{T}_{n}$ cage. The $\Delta E_{\text {comp }}$ is the energy accompanying the formation of complexes (exohedral and endohedral complexes, and the transition-state structures connecting them), and it is decomposed into two kinds of energy-(a) the deformation energy $\left(\Delta E_{\text {def }}\right)$ of the host cage caused by the complexation, and (b) the interaction energy $\left(\Delta E_{\text {int }}\right)$ between the guest species and the deformedhost cage:

$$
\Delta E_{\mathrm{comp}}=\Delta E_{\mathrm{def}}+\Delta E_{\mathrm{int}} .
$$

The former always brings about the destabilization of the system, but even the latter is possible to contribute the destabilization (repulsion) as well as the stabilization. The "minus" value means stabilization, while "plus" does destabilization of the system relative to the referred one for the binding energy $\left(\Delta E_{\text {comp }}\right)$ and both energy components, $\Delta E_{\text {def }}$ and $\Delta E_{\text {int }}$.

The $\Delta E_{\text {def }}$ is obtained as the energy difference between the deformed cage ( $\left.E_{\text {deformed cage }}\right)$ and the optimized (empty) one $\left(E_{\text {pure cage }}\right)$ :

$$
\Delta E_{\text {def }}=E_{\text {deformed cage }}-E_{\text {pure cage }} .
$$

On the other hand, the $\Delta E_{\text {int }}$ is defined as the energy difference between the complexes $\left(E_{\text {comp }}\right)$ and the sum of two energy components as shown as follows:

$$
\Delta E_{\text {int }}=E_{\text {comp }}-\left(E_{\text {deformed cage }}+E_{\text {guest species }}\right) .
$$

As a result, the $\Delta E_{\text {comp }}$ can be described as another formula as expected:

$$
\Delta E_{\text {comp }}=E_{\text {comp }}-\left(E_{\text {pure cage }}+E_{\text {guest species }}\right) .
$$

All calculations were performed with the Gaussian 03 [37] and GAMESS $[38,39]$ electronic structure codes.

\section{Results and Discussion}

3.1. Ti- $T_{8}$ versus $S i-T_{8}$. Before discussing the encapsulation reaction, it may be worth to compare some properties of the host molecule, $\mathrm{Ti}_{-} \mathrm{T}_{8},\left(\mathrm{HTiO}_{1.5}\right)_{8}$, with those of the $\mathrm{Si}$ analogue, $\mathrm{T}_{8},\left(\mathrm{HSiO}_{1.5}\right)_{8}$. Both molecules have highly symmetric $\mathrm{O}_{\mathrm{h}}$ structure [27]. The geometric parameters, the averaged NBO [40] and the Mulliken net atomic charge of the skeletal atoms, and the energy levels of the frontier orbitals (the Kohn-Sham orbitals in the DFT results) of both molecules are shown in Table 1 . As the table shows, all distances in $\mathrm{Ti}$ analogue are longer than those in $\mathrm{T}_{8}$, suggesting $\mathrm{Ti}-\mathrm{T}_{8}$ has the larger cavity compared to that of the Si analogue. It is convenient for the encapsulation of guest species as well as the extremely floppy titanoxane ( $\mathrm{Ti}-\mathrm{O}-\mathrm{Ti}$ ) bonds in the framework suggested by our previous study [27]. The two kinds of the bond angles, however, are very similar in both molecules. 


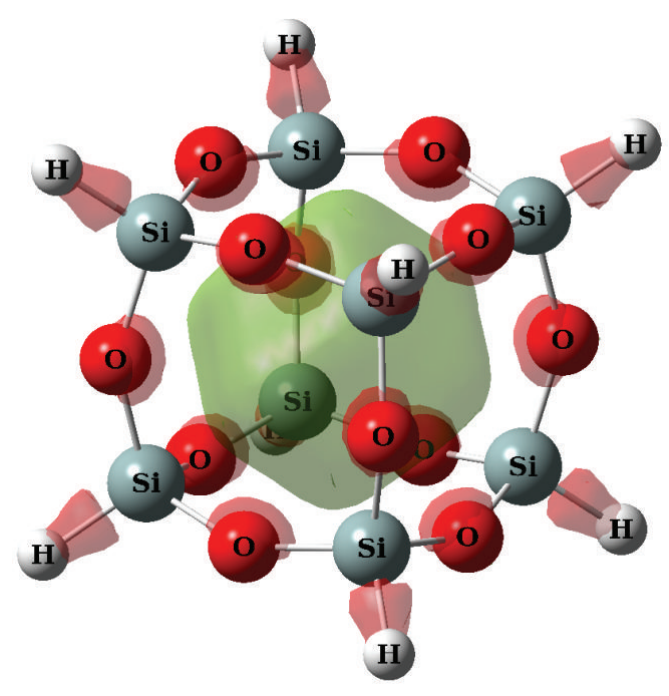

$\mathrm{Si}^{-\mathrm{T}_{8}} \mathrm{LUMO}$

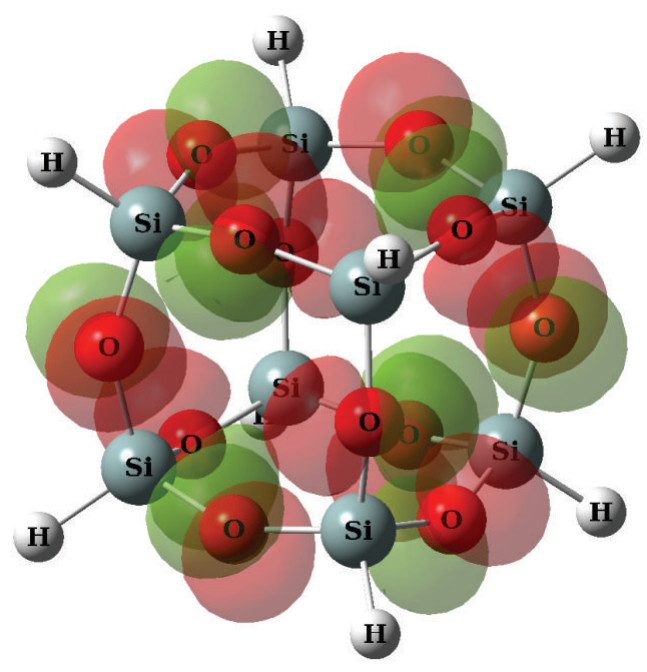

$\mathrm{Si}-\mathrm{T}_{8} \mathrm{HOMO}$

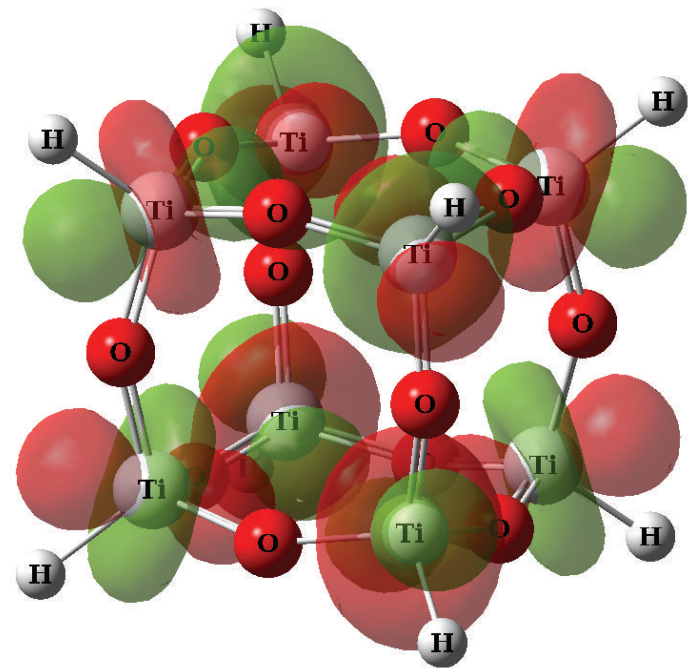

Ti-T 8 LUMO

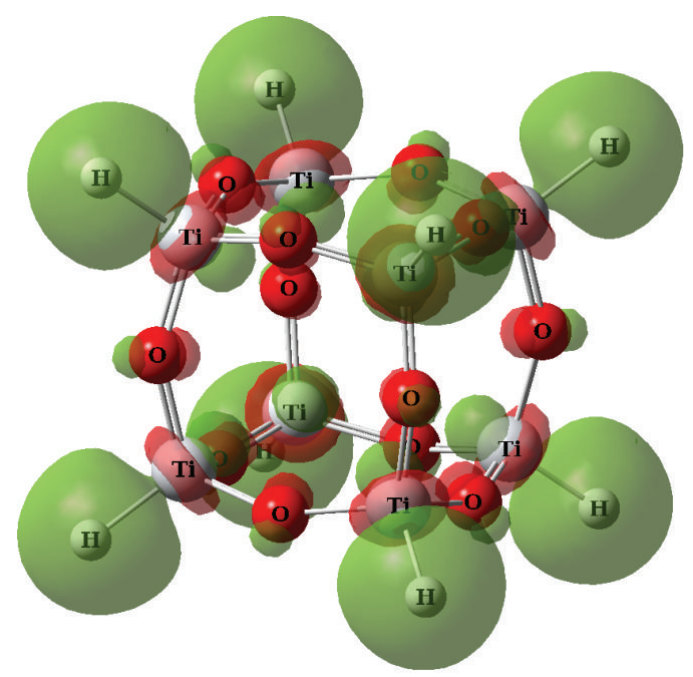

$\mathrm{Ti}^{-} \mathrm{T}_{8} \mathrm{HOMO}$

Figure 1: The HOMO and LUMO of $\mathrm{T}_{8}$ and $\mathrm{Ti}^{-} \mathrm{T}_{8}$ at the B3LYP/6-311+G(d) level.

In addition, the averaged net atomic charges in the table suggest that the $\mathrm{Ti}-\mathrm{O}$ bond is less polarized compared to the $\mathrm{Si}-\mathrm{O}$, which is in agreement with our previous results for the siloxane and titanoxane compounds $\left(\mathrm{H}(\mathrm{OH})_{2} \mathrm{XOX}(\mathrm{OH})_{2} \mathrm{H}\right.$; $\mathrm{X}=\mathrm{Si}$ and $\mathrm{Ti}$ ) [29]. In the Si/Ti-mixed POSS, however, Ti atom is found to have larger positive charge than that of $\mathrm{Si}$ atoms [27]. As the present basis set involves the diffuse functions, absolute values of the Mulliken charge seem to be remarkably underestimated compared to those of the NBO charge.

On the other hand, the B3LYP level significantly underestimates the HOMO-LUMO gap compared to the corresponding value obtained at the HF level, as expected. According to the HF results, the HOMO is higher and LUMO is lower in $\mathrm{Ti}^{-} \mathrm{T}_{8}$ than in $\mathrm{T}_{8}$, which makes the HOMO-LUMO energy gap of the $\mathrm{T}-\mathrm{T}_{8}$ slightly smaller compared to that of $T_{8}$. Nevertheless, the figures of the orbitals, especially for
HOMO, are very similar in the HF and B3LYP levels. As seen from Figure 1, the d orbitals on Ti atoms seem to play an important role for both frontier orbitals in $\mathrm{Ti}^{-} \mathrm{T}_{8}$ while the contribution of the p orbitals on oxygen atoms seems to be large in $\mathrm{T}_{8}$.

3.2. Insertion of Rare Gas Elements ( $\mathrm{He}, \mathrm{Ne}$, and $\mathrm{Ar}$ ). In Scheme 1 displayed is the schematic process of the insertion of some rare gas elements and cations into $\mathrm{Ti}^{-} \mathrm{T}_{8}$. As seen in the scheme, the guest species and $\mathrm{Ti}-\mathrm{T}_{8}$ form exohedral complex $\left(\mathrm{X}\left(\mathrm{Ti}-\mathrm{T}_{8}\right)\right)$ where the rare gas elements are above the center of a $\mathrm{D}_{4}\left((\mathrm{HTiO})_{4}\right)$ face of the cage first. Then the species inserts into the host cage via the transition-state structure with keeping the same $\mathrm{C}_{4 \mathrm{v}}$ symmetry as the first complex. The resultant endohedral complex $\left(\mathrm{X} @\left(\mathrm{Ti}-\mathrm{T}_{8}\right)\right)$ has the guest species in the center of the cage so the symmetry is as high as $\mathrm{D}_{4 \mathrm{~h}}\left(\mathrm{O}_{\mathrm{h}}\right)$. 


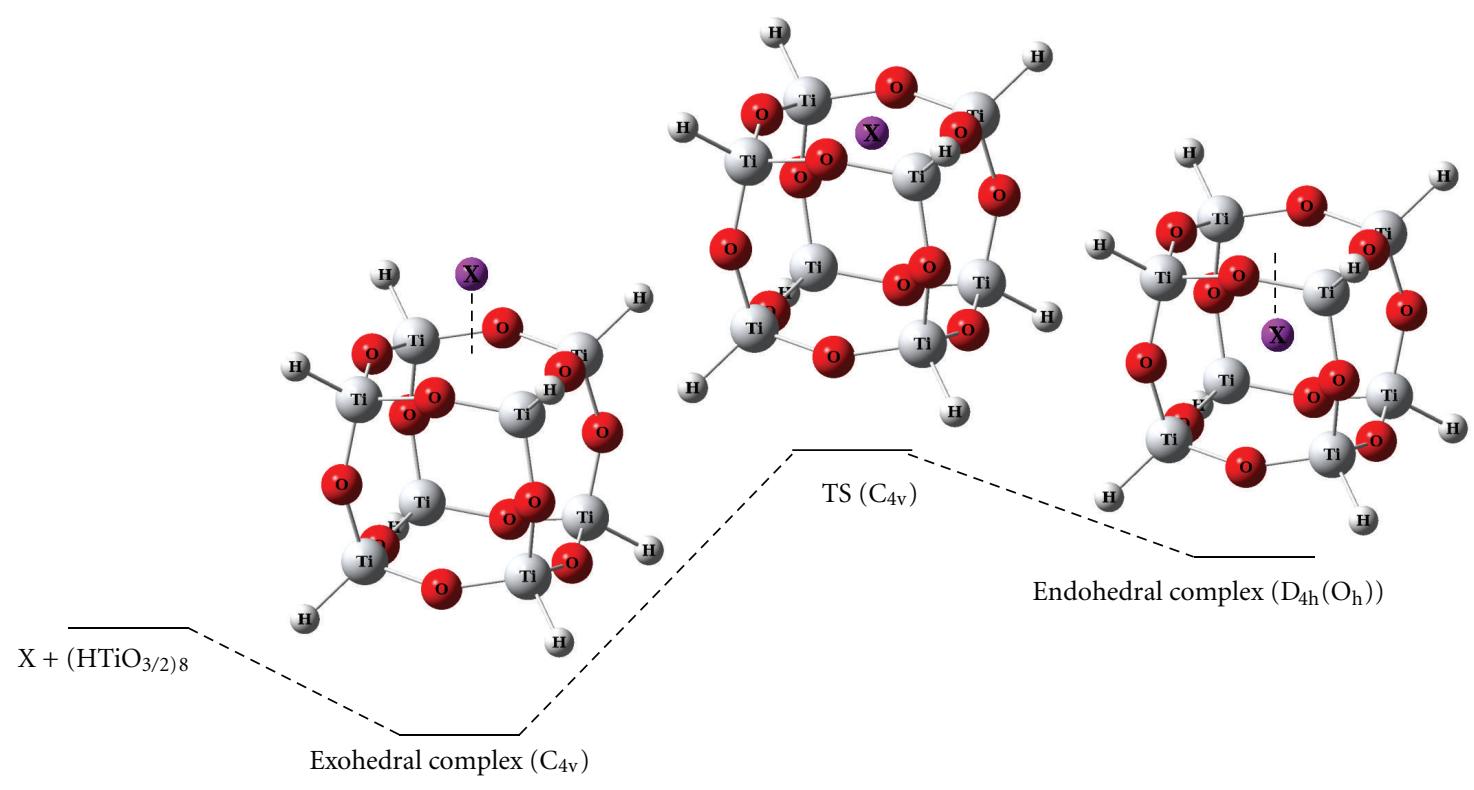

$\mathrm{X}=\mathrm{He}, \mathrm{Ne}, \mathrm{Ar}, \mathrm{Na}^{+}$, and $\mathrm{K}^{+}$

Scheme 1

The B3LYP/6-311+G(d) geometries of these structures are depicted in Tables 2 and 3. For the exohedral complexes, as Table 2 shows, the attached species $\mathrm{X}$ is far from the cage $(>3 \AA)$. Also, for the endohedral complexes, the geometry of the host cage does not largely change by the inclusion of guest species except for the heaviest rare gas element in this study, Ar atom. On the other hand, for the transitionstate structures (see Table 3 ), the geometry of the $\mathrm{D}_{4}$ face where the insertion takes place is remarkably expanded and the extent becomes large as the atomic radius of the guest element becomes large in the order $\mathrm{He}<\mathrm{Ne}<\mathrm{Ar}$ as expected. The other faces are not much affected as seen in the $\mathrm{H}_{2}$ insertion into POSS [18].

The energetics of the insertion reaction in Table 4 show that the energy barrier increases as the atomic radius of the guest element increases as expected from the geometrical change mentioned above. Apparently, the inclusion complex is less stable than the exohedral complex but that may be possible to exist because of the large release energy in all cases.

On the other hand, the binding energies $\left(\Delta E_{\text {comp }}\right)$ together with the result of energy decomposition are summarized in Table 5. For the rare gas elements, $\Delta E_{\text {comp }}$ and the two energy components $\left(\Delta E_{\text {def }}\right.$ and $\left.\Delta E_{\text {int }}\right)$ of the exohedral complex are very small. Furthermore, the absolute values of the deformation energy $\left(\Delta E_{\text {def }}\right)$ of the endohedral complex and the transition structure are much smaller than those of the interaction energy $\left(\Delta E_{\text {int }}\right)$. These results suggest that the encapsulation of the rare gas elements has just a small effect for the cage of $\mathrm{Ti}-\mathrm{T}_{8}$ and the origin of the binding energy is mainly the repulsion with the cage and not the deformation of the cage.
The reaction mechanism and the structures of the stationary points are similar to those of the $\mathrm{Si}$ analogue by Park et al. [9] .

3.3. Insertion of Cations of Alkali Metal Elements $\left(\mathrm{Li}^{+}, \mathrm{Na}^{+}\right.$, and $\mathrm{K}^{+}$). The insertion reaction discussed next is that of the cations of three alkali metal (group 1) elements. Among these, the reaction of the $\mathrm{Na}^{+}$and $\mathrm{K}^{+}$resembles that of the rare gas elements and the structures of the stationary points are also similar. For the exohedral complexes, the distance between the cations and the cage is smaller than that of the rare gases as shown in Table 2. The same is true in the $r(\mathrm{X}$ $\mathrm{O}$ ), while the opposite (longer) is seen in the $r(\mathrm{X}-\mathrm{Ti})$, for the endohedral complexes. This may be explained from the electrostatic interaction between the plus charge of the guest cations and skeletal $\mathrm{Ti}^{\delta+}$ and $\mathrm{O}^{\delta-}$ atoms of the host. Such interaction especially in the endohedral complex of $\mathrm{Na}$ cation is considered to be significant as the symmetry of the structure of $\mathrm{Na}^{+} @ \mathrm{Ti}-\mathrm{T}_{8}$ is reduced from $\mathrm{D}_{4 \mathrm{~h}}$ to $\mathrm{C}_{2 \mathrm{v}}$. This is in sharp contrast to the fact that the $\mathrm{Si}$ analogue keeps the highest symmetry in the endohedral complex, $\mathrm{Na}^{+} @ \mathrm{~T}_{8}$ [9].

In contrast, the both complexes of $\mathrm{Li}^{+}$are quite different with other cases as shown in Figure 2. There is another exohedral complex (exo-2) in addition to the normal $\mathrm{C}_{4 \mathrm{v}}$ structure (exo-1). As the figure shows, $\mathrm{Li}^{+}$is attached on one of the skeletal oxygen atoms in "exo-2" while the cation interacts with all oxygen atoms of the $\mathrm{D}_{4}$ face in "exo- 1 " and the former is $0.6 \mathrm{kcal} / \mathrm{mol}$ less stable than the latter. Furthermore, two types of the endohedral complex ("endo-1" and "endo$2 ")$ were located as in the case of the Si analogue [9]. The "endo-1" has the stretched cubic structure with the $\mathrm{D}_{4 \mathrm{~h}}$ symmetry, while in "endo-2" the cage is remarkably deformed 
TABLE 2: Some geometrical parameters ( $\AA$ and degrees) of X(Ti- $\left.\mathrm{T}_{8}\right)$ and $\mathrm{X} @\left(\mathrm{Ti}-\mathrm{T}_{8}\right) ; \mathrm{X}=\mathrm{He}, \mathrm{Ne}, \mathrm{Ar}, \mathrm{Na}^{+}, \mathrm{K}^{+}, \mathrm{Cl}^{-}$at the B3LYP/6-311+G(d) level.

\begin{tabular}{|c|c|c|c|c|c|c|c|c|c|c|}
\hline \multirow{2}{*}{$\mathrm{X}$} & \multicolumn{4}{|c|}{$\mathrm{X}\left(\mathrm{Ti}-\mathrm{T}_{8}\right)$ (exohedral complex) } & \multicolumn{6}{|c|}{$\mathrm{X} @\left(\mathrm{Ti}-\mathrm{T}_{8}\right)$ (endohedral complex) } \\
\hline & sym & $r\left(\mathrm{X}-\mathrm{S}^{\mathrm{a}}\right)$ & $r(\mathrm{X}-\mathrm{Ti})$ & $r(\mathrm{X}-\mathrm{O})$ & sym & $r\left(\mathrm{X}-\mathrm{S}^{\mathrm{a}}\right)$ & $r(\mathrm{X}-\mathrm{Ti})$ & $r(\mathrm{X}-\mathrm{O})$ & $<\mathrm{TiOTi}$ & $<\mathrm{OTiO}$ \\
\hline Pure & & & & & $\mathrm{D}_{4 \mathrm{~h}}$ & 1.746 & 3.023 & 2.950 & 149.1 & 109.1 \\
\hline $\mathrm{He}$ & $\mathrm{C}_{4 v}$ & 4.217 & 4.885 & 4.396 & $\mathrm{D}_{4 \mathrm{~h}}$ & 1.748 & 3.028 & 2.950 & 149.4 & 108.9 \\
\hline $\mathrm{Ne}$ & $\mathrm{C}_{4 v}$ & 3.504 & 4.284 & 3.782 & $\mathrm{D}_{4 \mathrm{~h}}$ & 1.750 & 3.031 & 2.954 & 149.3 & 109.0 \\
\hline $\mathrm{Ar}$ & $\mathrm{C}_{4 v}$ & 5.292 & 5.838 & 5.365 & $\mathrm{D}_{4 \mathrm{~h}}$ & 1.757 & 3.043 & 2.975 & 148.8 & 109.3 \\
\hline $\mathrm{Na}^{+}$ & $\mathrm{C}_{4 v}$ & 2.119 & 3.247 & 2.545 & $\mathrm{C}_{2 v}$ & 1.716 & 3.069 & 2.595 & 154.9 & 103.1 \\
\hline $\mathrm{K}^{+}$ & $\mathrm{C}_{4 v}$ & 2.769 & 3.698 & 3.028 & $\mathrm{D}_{4 \mathrm{~h}}$ & 1.790 & 3.101 & 2.892 & 157.2 & 104.7 \\
\hline $\mathrm{Cl}^{-}$ & & & & & $\mathrm{D}_{4 \mathrm{~h}}$ & 1.707 & 2.959 & 3.053 & 139.1 & 113.7 \\
\hline
\end{tabular}

${ }^{\mathrm{a}}$ The center of a $\mathrm{D}_{4}$ face.

TABLE 3: Some geometrical parameters ( $\AA$ and degrees) of the $\mathrm{D}_{4}$ face where the insertion takes place in the transition structure connecting $\mathrm{X}(\mathrm{Ti}-\mathrm{T} 8)$ and X@(Ti-T8); X= He, Ne, Ar, Na+ $\mathrm{K}^{+}, \mathrm{Cl}^{-}$at the B3LYP/6-311+G(d) level.

\begin{tabular}{llcccrc}
\hline $\mathrm{X}$ & sym & $r(\mathrm{X}-\mathrm{Ti})$ & $r(\mathrm{X}-\mathrm{O})$ & $r(\mathrm{Ti}-\mathrm{O})$ & $<\mathrm{TiOTi}$ & 149.1 \\
\hline Pure & $\mathrm{D}_{4 \mathrm{~h}}$ & 2.468 & 2.114 & 1.811 & 1.833 & 148.4 \\
$\mathrm{He}$ & $\mathrm{C}_{4 v}$ & 2.503 & 2.160 & 1.860 & 143.5 & 112.7 \\
$\mathrm{Ne}$ & $\mathrm{C}_{4 v}$ & 2.510 & 2.267 & 1.924 & 138.7 & 119.0 \\
$\mathrm{Ar}$ & $\mathrm{C}_{4 v}$ & 2.553 & 2.431 & 1.889 & 126.5 \\
$\mathrm{Na}^{+}$ & $\mathrm{C}_{4 v}$ & 2.629 & 2.107 & 1.951 & 159.6 & 150.7 \\
$\mathrm{~K}^{+}$ & $\mathrm{C}_{4 v}$ & 2.676 & 2.507 & 1.906 & 129.5 & 112.7 \\
$\mathrm{Cl}^{-}$ & $\mathrm{C}_{4 v}$ & 2.440 & & & 136.7 \\
\hline
\end{tabular}

TABLE 4: The B3LYP/6-311+G(d)+ZPC relative energy ( $\mathrm{kcal} / \mathrm{mol})$ of the exohedral (X(Ti-T8)) and endohedral (X@(Ti-T8)) complexes $\left(\mathrm{X}=\mathrm{He}, \mathrm{Ne}, \mathrm{Ar}, \mathrm{Li}^{+}, \mathrm{Na}^{+}, \mathrm{K}^{+}\right.$, and $\left.\mathrm{Cl}^{-}\right)$and the transition state (TS) connecting them and the release energy $(\Delta E)$ of $\mathrm{X}$ from the endohedral complex.

\begin{tabular}{lcccc}
\hline $\mathrm{X}$ & $\mathrm{X}\left(\mathrm{Ti}-\mathrm{T}_{8}\right)$ & $\mathrm{TS}$ & $\mathrm{X} @\left(\mathrm{Ti}-\mathrm{T}_{8}\right)$ & $\mathrm{Release} \Delta E$ \\
\hline $\mathrm{He}$ & 0.0 & 31.2 & 7.6 & 21.6 \\
$\mathrm{Ne}$ & 0.0 & 58.3 & 46.0 & 46.7 \\
$\mathrm{Ar}$ & 0.0 & 145.2 & 25.8 & 99.2 \\
$\mathrm{Li}^{+}$ & 0.0 & 27.8 & 31.7 & 2.0 \\
$\mathrm{Na}^{+}$ & 0.0 & 60.7 & 53.6 & 29.0 \\
$\mathrm{~K}^{+}$ & 0.0 & 150.9 & 7.7 & 97.3 \\
$\mathrm{Cl}^{-}$ & 0.0 & 83.5 & 75.8 \\
\hline
\end{tabular}

compared to "endo-1." The large deformation of the cage in both structures is brought about by the strong interaction between $\mathrm{Li}^{+}$and skeletal oxygens as indicated by the short LiO distances of 2.181 and $2.081 \AA$ in the planar or tetrahedral $\mathrm{Li}^{+} \mathrm{O}_{4}$ moiety of "endo-1" and "endo-2," respectively. As a result, the symmetry of "endo-2" is reduced to $\mathrm{D}_{2 \mathrm{~d}}$, and this is found to be more stable than "endo- 1 " by $2.2 \mathrm{kcal} / \mathrm{mol}$ at the B3LYP/6-311+G(d) +ZPC level. These are the same trend in the $\mathrm{Li}^{+} @ \mathrm{~T}_{8}[9]$.

Figure 3 shows the potential energy surface of the insertion of $\mathrm{Li}^{+}$into $\mathrm{Ti}-\mathrm{T}_{8}$. The exo- 2 and endo- 1 are not involved in the figure. It is noteworthy that $\mathrm{Li}^{+}$seems to keep some interaction with several specific oxygens during the insertion process as the transition-state structure is not symmetric with respect to the center.

The energetics of the insertion reaction of these cations can be compared with those of rare gas elements in Table 4.
The energy changes with regard to atomic number in both groups resemble each other. As the atom becomes heavy in each group, the energy barrier becomes high and the endohedral complex becomes less stable. However, the stability of the endohedral complex relative to the exohedral complex is smaller in the cations compared to the rare gas elements. For the case of $\mathrm{Li}^{+}$, especially the release energy is too small $(2.0 \mathrm{kcal} / \mathrm{mol})$ for $\mathrm{Li}^{+} @ \mathrm{Ti}-\mathrm{T}_{8}$ to exist stably. As a result, for the encapsulation of $\mathrm{Li}^{+}$in $\mathrm{Ti}-\mathrm{T}_{8}$, only the exohedral complex is predicted to be existable. On the other hand, the endohedral complex of the other cations is kinetically existable but the energy barrier is too high for the exohedral complex to isomerize to the endohedral complex at least in the room temperature.

As Table 5 shows, the deformation energy $\left(\Delta E_{\mathrm{def}}\right)$ of the exohedral complex of the cations is much larger than that of the rare gas elements as expected from the significant 
TABle 5: Energy decomposition of the binding energy $\left(\Delta E_{\text {comp }}\right)(\mathrm{kcal} / \mathrm{mol})$ of the complexes of various guest species and Ti-T8 and the transition state connecting the complexes at the B3LYP/6-311+G(d) level.

\begin{tabular}{|c|c|c|c|c|c|c|}
\hline & $\mathrm{X}$ & sym & $\Delta E_{\mathrm{def}}$ & $\Delta E_{\text {int }}$ & $\Delta E_{\text {comp }}$ & $\Delta E_{\text {comp }}+\mathrm{ZPC}$ \\
\hline \multirow{7}{*}{ Exo } & $\mathrm{He}$ & $\mathrm{C}_{4 v}$ & 0.0 & -0.2 & -0.2 & -0.1 \\
\hline & $\mathrm{Ne}$ & $\mathrm{C}_{4 v}$ & 0.0 & -0.3 & -0.3 & -0.2 \\
\hline & $\mathrm{Ar}$ & $\mathrm{C}_{4 v}$ & 0.0 & 0.0 & 0.0 & 0.0 \\
\hline & $\mathrm{Li}^{+}$ & $\mathrm{C}_{4 v} / \mathrm{C}_{1}$ & $17.4 / 11.8$ & $-56.9 /-50.6$ & $-39.5 /-38.8$ & $-38.1 /-37.5$ \\
\hline & $\mathrm{Na}^{+}$ & $\mathrm{C}_{4 v}$ & 11.7 & -33.9 & -22.2 & -21.6 \\
\hline & $\mathrm{K}^{+}$ & $\mathrm{C}_{4 v}$ & 7.9 & -19.9 & -12.0 & -11.8 \\
\hline & $\mathrm{Cl}^{-}$ & Cs & 35.9 & -93.6 & -57.7 & -57.4 \\
\hline \multirow{7}{*}{ Endo } & $\mathrm{He}$ & $\mathrm{D}_{4 \mathrm{~h}}$ & 0.1 & 6.6 & 6.7 & 7.5 \\
\hline & $\mathrm{Ne}$ & $\mathrm{D}_{4 \mathrm{~h}}$ & 0.1 & 10.6 & 10.7 & 11.4 \\
\hline & $\mathrm{Ar}$ & $\mathrm{D}_{4 \mathrm{~h}}$ & 1.4 & 43.7 & 45.1 & 46.0 \\
\hline & $\mathrm{Li}^{+}$ & $\mathrm{D}_{2 \mathrm{~d}} / \mathrm{D}_{4 \mathrm{~h}}$ & $31.9 / 27.7$ & $-45.9 /-39.0$ & $-14.0 /-11.3$ & $-12.3 /-10.1$ \\
\hline & $\mathrm{Na}^{+}$ & $\mathrm{C}_{2 v}$ & 16.3 & -6.6 & 9.7 & 10.1 \\
\hline & $\mathrm{K}^{+}$ & $\mathrm{D}_{4 \mathrm{~h}}$ & 15.4 & 25.7 & 41.1 & 41.8 \\
\hline & $\mathrm{Cl}^{-}$ & $\mathrm{D}_{4 \mathrm{~h}}$ & 17.3 & -67.5 & -50.2 & -49.7 \\
\hline \multirow{8}{*}{ TS } & $\mathrm{He}$ & $\mathrm{C}_{4 v}$ & 2.0 & 27.3 & 29.3 & 31.1 \\
\hline & $\mathrm{Ne}$ & $\mathrm{C}_{4 v}$ & 10.2 & 47.0 & 57.2 & 58.1 \\
\hline & $\mathrm{Ar}$ & $\mathrm{C}_{4 v}$ & 39.4 & 106.0 & 145.4 & 145.2 \\
\hline & $\mathrm{Li}^{+}$ & $\mathrm{C}_{\mathrm{s}}$ & 28.3 & -40.0 & -11.7 & -10.3 \\
\hline & $\mathrm{Na}^{+}$ & $\mathrm{C}_{4 v}$ & 22.2 & 15.6 & 37.8 & 39.1 \\
\hline & $\mathrm{K}^{+}$ & $\mathrm{C}_{4 v}$ & 45.6 & 93.7 & 139.3 & 139.1 \\
\hline & $\mathrm{F}^{-}$ & $\mathrm{C}_{1} / \mathrm{C}_{1}$ & $50.6 / 52.8$ & $-136.9 /-131.6$ & $-86.3 /-78.8$ & $-85.7 /-77.9$ \\
\hline & $\mathrm{Cl}^{-}$ & $\mathrm{C}_{4 v}$ & 59.0 & -32.2 & 26.8 & 26.1 \\
\hline
\end{tabular}

geometrical changes mentioned above. The host cage is considerably destabilized as suggested by the large value of $\Delta E_{\text {def }}$, but the stabilization by $\Delta E_{\text {int }}$ overwhelms the disadvantage so the complex becomes more stable than the isolated cation and cage eventually in all cases. The large plus values of $\Delta E_{\text {def }}$ (destabilization) and large minus values of $\Delta E_{\text {int }}$ (stabilization) in the cation complexes compared to those of the rare gases may be explained from the electrostatic interaction between the plus charge of the cations and the skeletal elements. For all stationary points of the cations, as ionic radius becomes small, $\Delta E_{\text {def }}$ becomes large (destabilized) and $\Delta E_{\text {int }}$ becomes small (largely minus, stabilized) except for $\Delta E_{\text {def }}$ of the transition-state structure of $\mathrm{K}^{+}$. Here, it may be interesting to compare the $\Delta E_{\text {int }}$ of isoelectronic pairs, $\mathrm{He} / \mathrm{Li}^{+}, \mathrm{Ne} / \mathrm{Na}^{+}$, and $\mathrm{Ar} / \mathrm{K}^{+}$. The $\mathrm{NBO}$ analyses [40] show the plus charge of the free cations (formally 1 ) is significantly reduced by the complexation, such as $\mathrm{Li}^{+}$(exo-1/exo$2: 0.777 / 0.912$, end-1/endo-2:0.509/0.495), $\mathrm{Na}^{+}$(exo: 0.883, endo: 0.484 ), and $\mathrm{K}^{+}$(exo: 0.943 , endo: 0.558 ), suggesting the considerable electrostatic interaction with the host cage and this brings about the large stability of the complexes indicated by the largely minus $\Delta E_{\text {comp }}$.

For the endohedral complex of the cations, however, the destabilization caused by the significant geometrical changes mentioned above is more serious compared to the exohedral complexes, as indicated by the larger value of $\Delta E_{\text {def }}$. The strong interaction between the cations and skeletal atoms may be the main reason for the large $\Delta E_{\text {def }}$ as suggested from the geometrical parameters in Table 2 . As a result, $\Delta E_{\mathrm{comp}}$ is still minus for the $\mathrm{Li}^{+} @ \mathrm{Ti}^{-} \mathrm{T}_{8}$ while $\mathrm{K}^{+} @ \mathrm{Ti}-\mathrm{T}_{8}$ gives remarkably plus value so severe steric repulsion between the guest with large ionic radius and host may be expected in the case of $\mathrm{K}^{+}$. The value of $\mathrm{Na}^{+} @ \mathrm{Ti}-\mathrm{T}_{8}$ is the intermediate between the cases of $\mathrm{Li}^{+}$and $\mathrm{K}^{+}$. Incidentally, $\Delta E_{\text {comp }}$ of the transitionstate structure for the $\mathrm{Li}^{+}$case is minus, -11.7 ( -10.3 with $\mathrm{ZPC}$ ) $\mathrm{kcal} / \mathrm{mol}$, too. This minus value is caused by the largely minus $\Delta E_{\text {int }}$ as shown in Table 5 . This stabilization may be explained from the unique structure (Figures 2 and 3 ) mentioned above and makes the TS of the insertion of $\mathrm{Li}^{+}$ lower compared to that of the other cations and the endohedral complex kinetically unstable.

3.4. Insertion of Anions of Halogen Elements ( $\mathrm{F}^{-}$and $\mathrm{Cl}^{-}$). Next guests are the minus ions of halogen (group 7). The structures of the complexes and reaction paths of the halogen anions investigated here (especially $\mathrm{F}^{-}$) are significantly different with those of the rare gas or cationic elements in the preceding sections. Incidentally, there are many comprehensive studies for the encapsulation of $\mathrm{F}^{-}$into POSS, and it is well known that the endohedral complex $\mathrm{F}^{-} @ \mathrm{~T}_{8}$ has been observed experimentally [7, 8, 12].

First, the properties of the complexes between the halogen anions and $\mathrm{Ti}$ cage are explained in detail. For $\mathrm{F}^{-}$, as Figure 4 shows, various kinds of exohedral $((a)-(d))$ and endohedral (e) complexes were located but we could not find the exohedral structure with the higher $\mathrm{C}_{4 \mathrm{v}}$ symmetry like the rare gas or cationic species. $\mathrm{F}^{-}$tends to interact strongly with small number ( 1 or 2 ) of skeletal $\mathrm{Ti}$ atoms. Among 


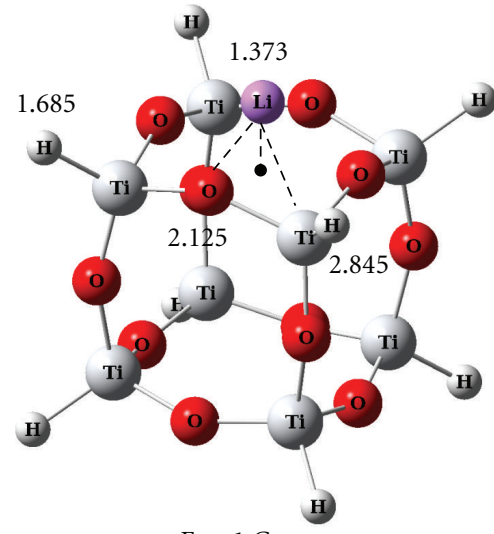

Exo-1 $\mathrm{C}_{4 \mathrm{v}}$

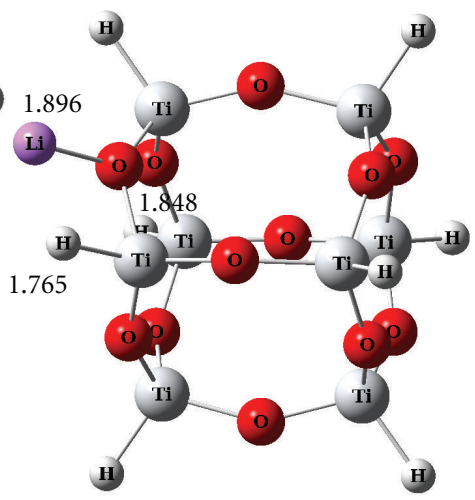

Exo-2 $\mathrm{C}_{1}$

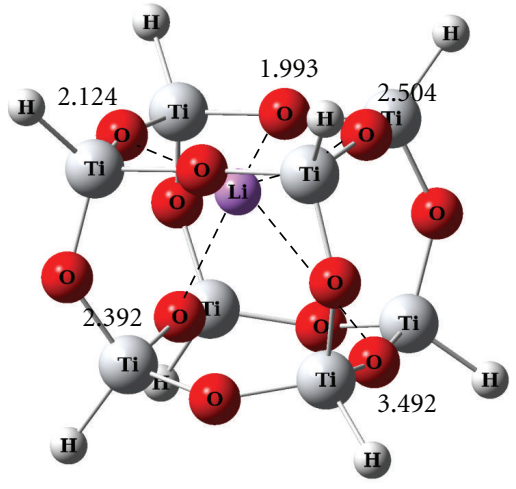

TS connecting exo-1 and endo-2

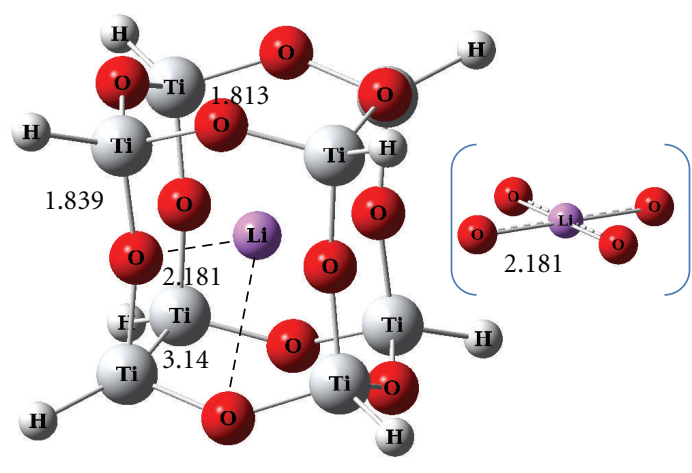

Endo-1 $\mathrm{D}_{4 \mathrm{~h}}$

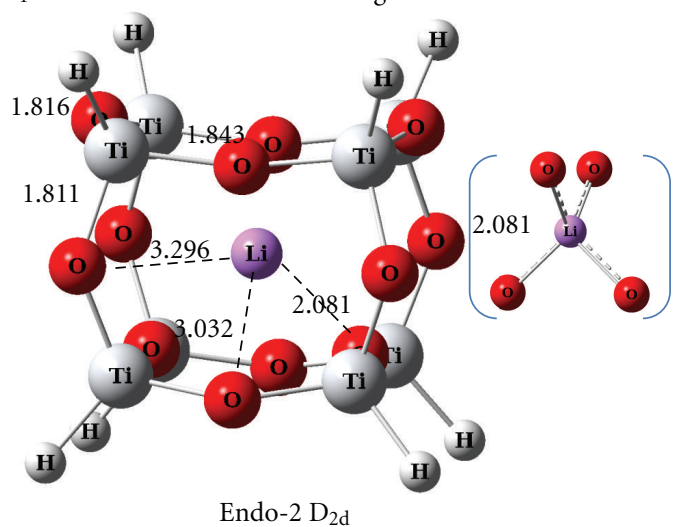

FIGURE 2: The B3LYP/6-311+G(d) optimized geometries of the exohedral and endohedral complexes and the transition state connecting "Exo-1" and "Endo-2" of $\mathrm{Li}^{+}$and $\mathrm{Ti}-\mathrm{T}_{8}$ in angstroms.

these, (a) and (b) have the partial triangular bipyramidal structure so we call each of them as "axial" and "equatorial" complex, respectively (see Scheme 2). The similar exohedral complexes are observed in the $\mathrm{Si}$ analogue too, though the "equatorial" conformation is not an equilibrium structure [9]. $\mathrm{F}^{-}$interacts with one $\mathrm{Ti}$ atom in (a) and (b) while it does with more than two Ti atoms in the others in Figure 4. Apparently in the diagonally bridged structures, "diagonalbridge" (d), the Ti- $\mathrm{T}_{8}$ cage is considerably deformed as suggesting with the largest $\Delta E_{\text {def }}$, so it is remarkably less stable than other isomers as seen in Table 6.

On the other hand, the structure of the endohedral complex "endo" (e) is quite interesting since $\mathrm{F}^{-}$is notthe center of the cage but close to a specific skeletal $\mathrm{Ti}$ atom, which is completely different with the initial expectation. As a result, this complex also seems to have the partial triangular bipyramidal structure with $\mathrm{F}^{-}$at the axial position in a corner of the cage. This is also different with the fact that the $\mathrm{F}^{-}$is encapsulated in the center of the silicon analogue, $\mathrm{T}_{8}$ [9]. Nevertheless, Tossell has found that in the larger POSS such as $\mathrm{T}_{10}$ and $\mathrm{T}_{12}$ with the double-decker structure $\mathrm{F}^{-}$is bound at the Si atom in a corner of the cage so the present result resembles that [12].

The distance between $\mathrm{F}^{-}$and the $\mathrm{Ti}$ in (e) is $2.321 \AA$ so it is rather longer than $1.814 \AA$ in (a). As apparent from Table 6 , the smallest deformation energy among the isomers suggests that this structure does not bring about such a severe energetic damage of the cage seen in the other structures. That is the reason why the endohedral complex (e) is most stable in spite of the smallest interaction energy among the five isomers. The relative stability was found to increase $(-3.2$ to $-7.6 \mathrm{kcal} / \mathrm{mol})$ at the more reliable MP2 level. In order to confirm whether the small space of $\mathrm{T}_{8}$ triggers such a unique structure, we have investigated the case of larger $\mathrm{Ti}^{-} \mathrm{T}_{10}$. However, as Figure S1 (in Supporting Information available online at doi:10.1155/2012/391325) shows, the similar endohedral (endo) complex was also located, and the F-Ti distance is ca. $0.1 \AA$ shorter than that in "endo" (e) of $\mathrm{Ti}^{-} \mathrm{T}_{8}$. Interestingly, in contrast, it is found that $\mathrm{Ti}^{-\mathrm{T}_{6}}$ with a smaller titanoxane cage (a prismatic shape) has a $\mathrm{F}^{-}$in the center of the cage like in the case of $\mathrm{F}^{-} @ \mathrm{~T}_{8}$ at the same B3LYP/6-311+G(d) level (see Figure S2). This means the cavity of $\mathrm{Ti}^{-} \mathrm{T}_{8}$ is large enough for a $\mathrm{F}^{-}$moves rather freely compared with that of $\mathrm{Ti}^{-} \mathrm{T}_{6}$. Therefore, the limited space of $\mathrm{Ti}^{-} \mathrm{T}_{8}$ is found not to be the reason for the strange behavior of $\mathrm{F}^{-}$in the endohedral complex but the strong electrostatic interaction between $\mathrm{F}^{-}$and $\mathrm{Ti}$ atom of Ti-T $\mathrm{T}_{n}(n=8$ and 10) may be the plausible explanation. Furthermore, in consideration of the Tossell results for $\mathrm{F}^{-} @ \mathrm{~T}_{n}(n=10$ and 12) $[12], \mathrm{F}^{-}$seems to prefer to interact with a specific Ti or Si rather than with plural skeletal atoms at the same time if there is enough space to allow that in the cage. 


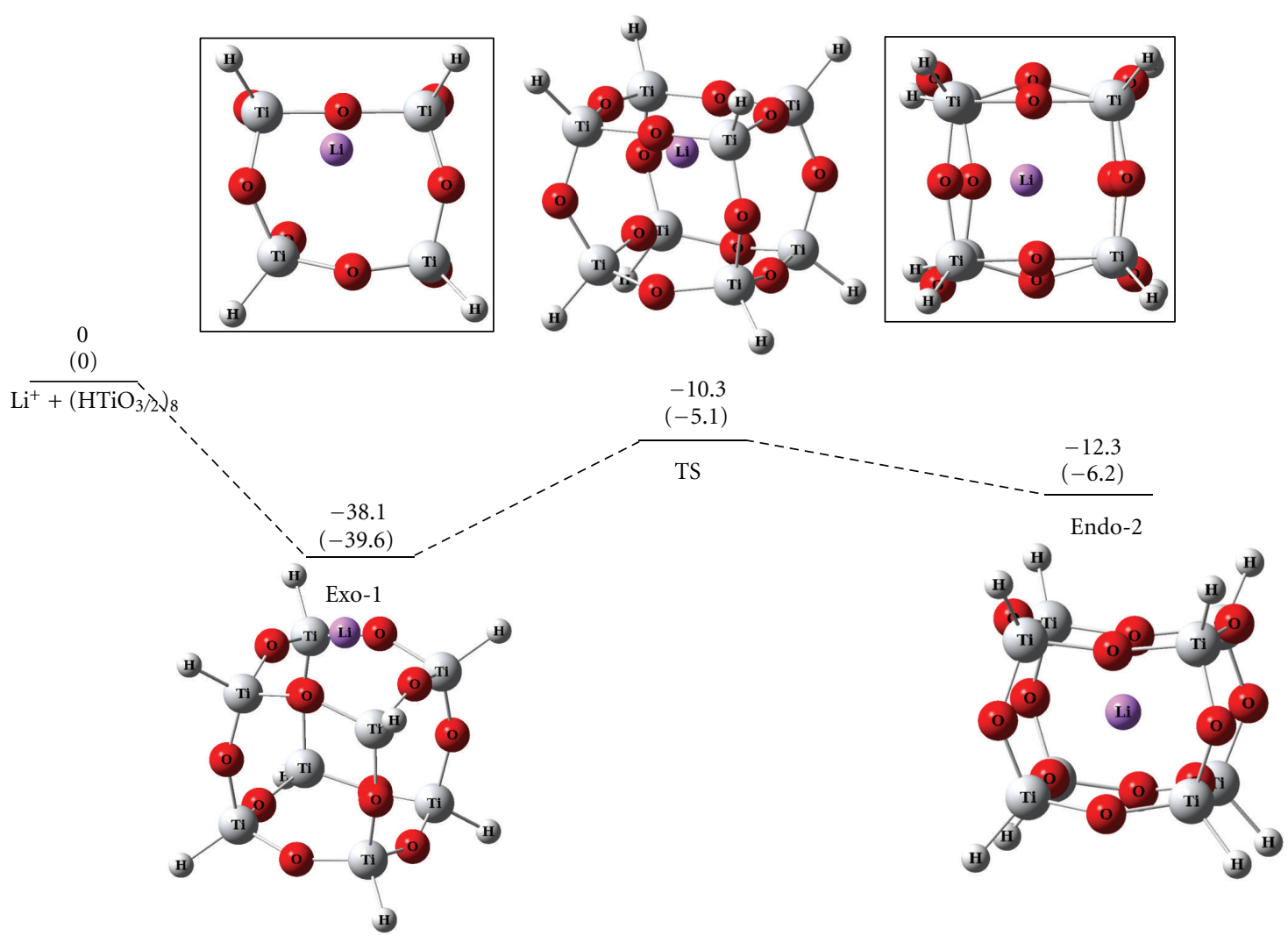

Figure 3: The potential energy surface $(\mathrm{kcal} / \mathrm{mol})$ of the insertion reaction of $\mathrm{Li}^{+}$into $\mathrm{Ti}^{-} \mathrm{T}_{8}$ with the structures of the exohedral complex (Exo-1), the transition state (TS), and endohedral complex (Endo-2) at the B3LYP/6-311+G(d) +ZPC and HF/6-311+G(d)+ZPC (in parentheses) levels. For the transition state, the side view is in the left quadrangle while the top view is in the right one.

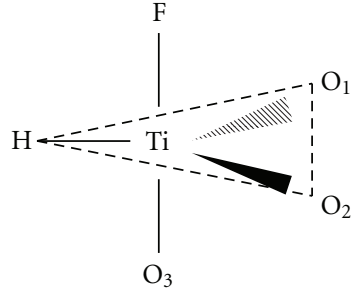

Axial

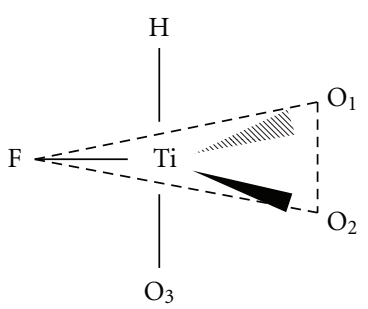

Equatorial

Scheme 2

On the other hand, the isomerization between "axial" and "equatorial" exohedral complexes of $\mathrm{F}^{-}\left(\mathrm{Ti}-\mathrm{T}_{8}\right)$ takes place via the transition structure also shown in Figure 4. The "equatorial" structure is less stable than "axial" by 3.6 (2.7 at the HF/6-311+G(d)+ZPC level) $\mathrm{kcal} / \mathrm{mol}$ at the B3LYP/6$311+G(d)+Z P C$ level, while the extremely low energy barrier $(0.3 \mathrm{kcal} / \mathrm{mol}$ at the HF level) needed for the isomerization to "axial" is further reduced to less than $0.1 \mathrm{kcal} / \mathrm{mol}$ at the B3LYP level. Therefore, for the exohedral complex of $\mathrm{F}^{-}$(Ti$\mathrm{T}_{8}$ ), "axial" is the main structure but the interconversion of the two conformations is possible to take place very easily.

In contrast with the $\mathrm{F}^{-}$case, the situation of the encapsulation of $\mathrm{Cl}^{-}$into Ti-T $\mathrm{T}_{8}$ cage is quite simple. The "axial" is a unique exohedral complex and the endohedral complex has a $\mathrm{Cl}^{-}$at the center of the cage with the $\mathrm{D}_{4 \mathrm{~h}}$ symmetry like those of the rare gases and $\mathrm{K}^{+}$as shown in Figure 5. As seen from Table 4, the endohedral complex is less stable only by $7.7 \mathrm{kcal} / \mathrm{mol}$ than the exohedral complex. This is in sharp contrast with the fact that the endohedral complex is largely less stable than the exohedral complex in the isoelectronic Ar and $\mathrm{K}^{+}$as shown in Table 4. This is explained from the small $\Delta E_{\text {def }}(17.3 \mathrm{kcal} / \mathrm{mol})$ and large absolute value of the $\Delta E_{\text {int }}$ $(-67.5 \mathrm{kcal} / \mathrm{mol})$ of the endohedral complex of $\mathrm{Cl}^{-} @ \mathrm{Ti}^{-} \mathrm{T}_{8}$ (see Table 5). As a result, the endohedral complex is not so unstable compared to the other cases.

Incidentally, the deformation energy ( $\left.\Delta E_{\text {def }}\right)$ of the complexes of $\mathrm{F}^{-}$and $\mathrm{Ti}-\mathrm{T}_{8}$ is larger than that of the complexes of $\mathrm{Cl}^{-}$and $\mathrm{Ti}-\mathrm{T}_{8}$ probably because of the larger geometrical 


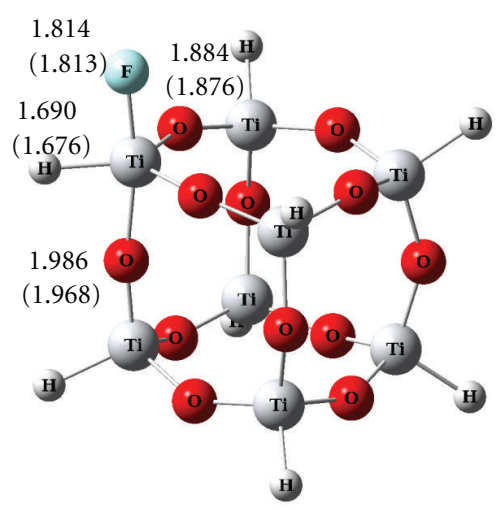

(a) Axial $\mathrm{C}_{1}$

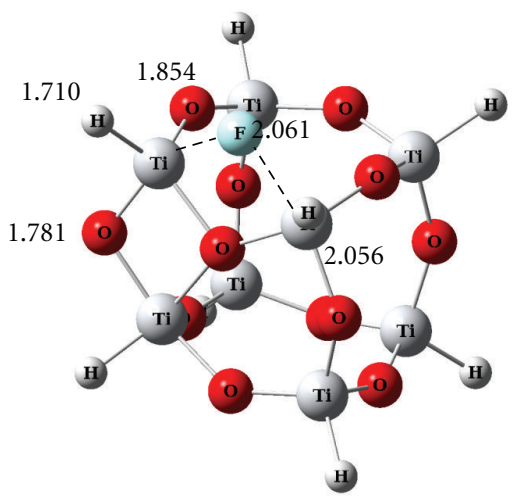

(c) Neighbor-bridge $\mathrm{C}_{1}$

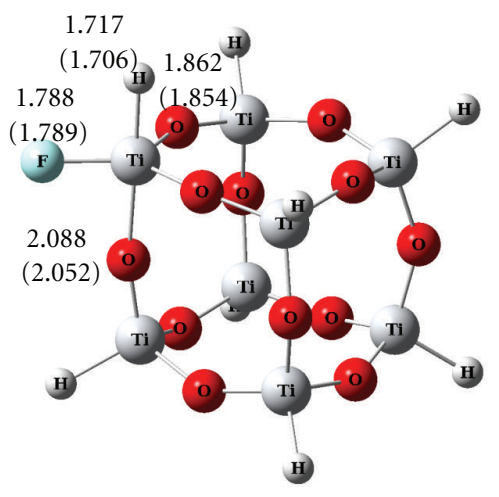

(b) Equatorial $C_{S}$

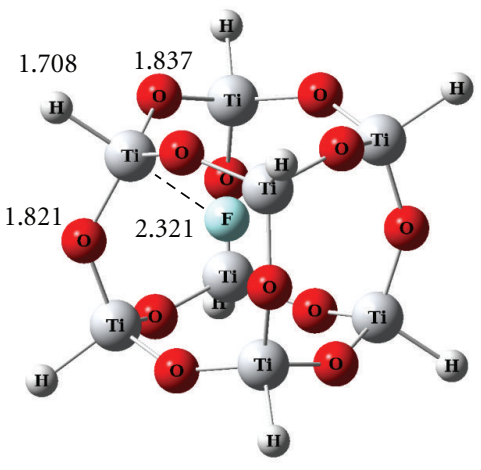

(e) Edo $C_{1}$

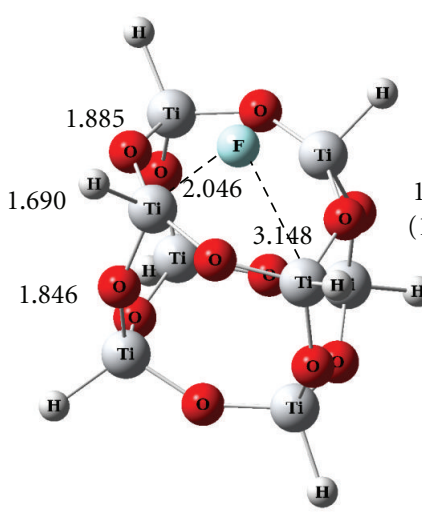

(d) Diagonal-bridge $\mathrm{C}_{2 \mathrm{v}}$

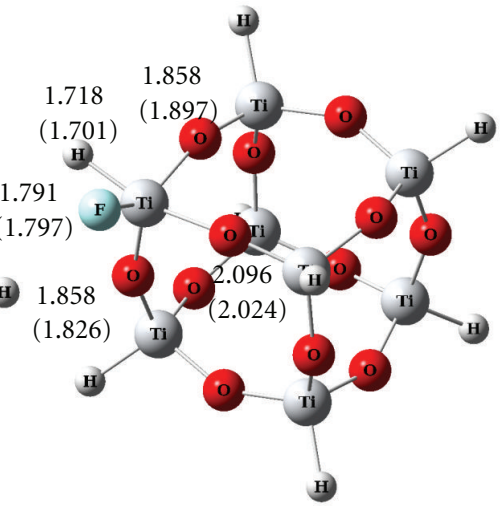

TS connecting (a) and (b)

Figure 4: The B3LYP/6-311+G(d) and HF/6-311+G(d) (in parentheses) optimized geometries of exohedral and endohedral complexes of $\mathrm{F}^{-}$and $\mathrm{Ti}-\mathrm{T}_{8}$ and the transition state for the "Axial" (a) "Equatorial" (b) isomerization in angstroms.

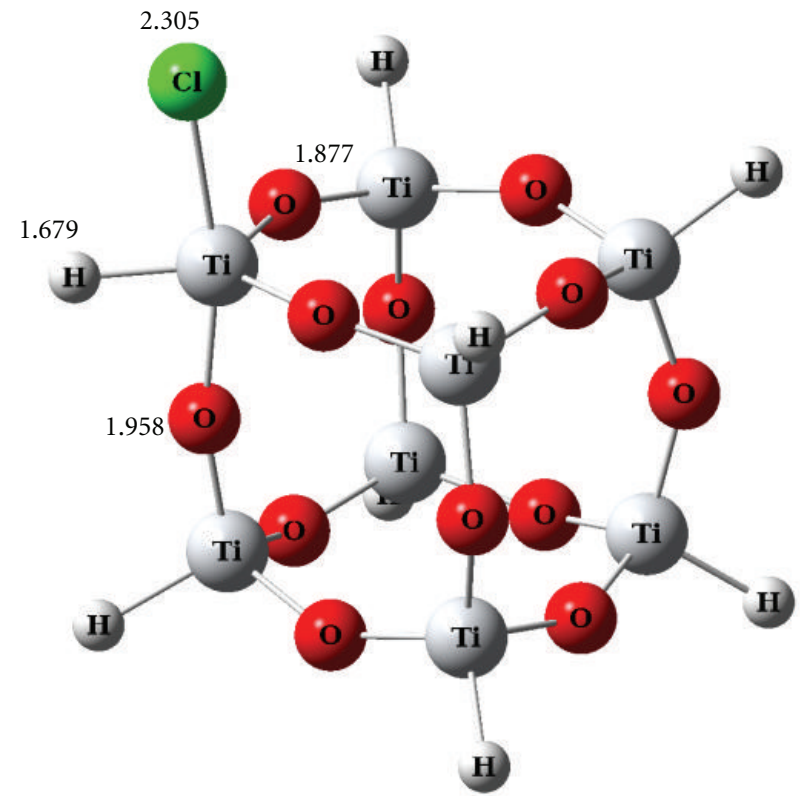

(a) Axial $C_{s}$

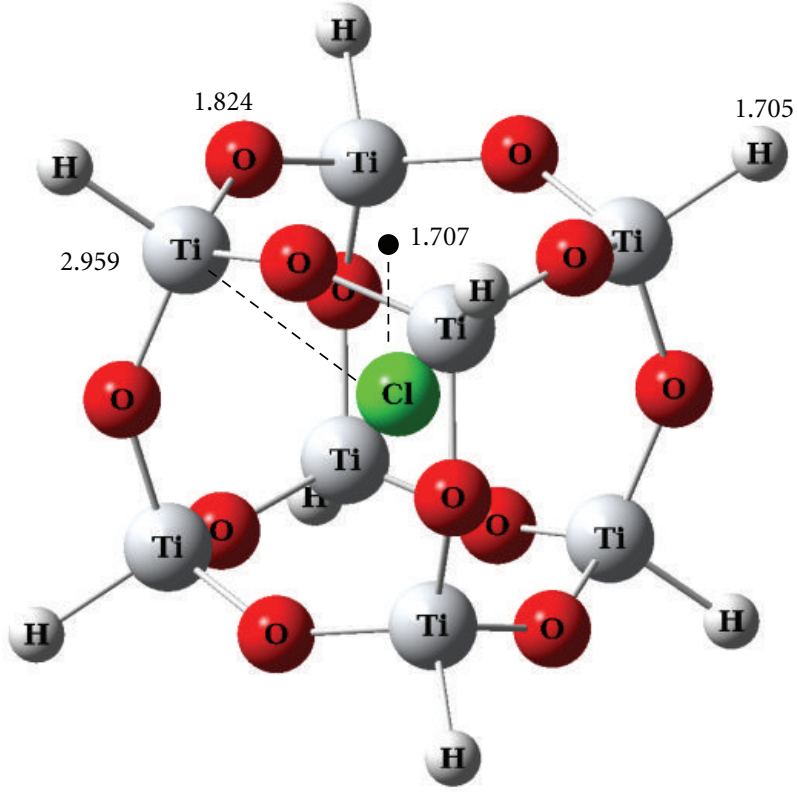

(b) Endo $\mathrm{D}_{4 h}$

Figure 5: The B3LYP/6-311+G(d) optimized geometries of the exohedral (Axial) and endohedral (Endo) complexes of $\mathrm{Cl}^{-}$and $\mathrm{Ti}^{-} \mathrm{T}_{8}$ in angstroms. 
TABle 6: Energy decomposition of the binding energy $\left(\Delta E_{\text {comp }}\right)(\mathrm{kcal} / \mathrm{mol})$ of the complexes of $\mathrm{F}^{-}$and Ti- $\mathrm{T}_{8}$ and the energies relative to "axial" $(\Delta E)$ in each system based on the B3LYP/6-311+G(d)+ZPC and MP2/6-311+G(d)//B3LYP/6-311+G(d) energies.

\begin{tabular}{|c|c|c|c|c|c|c|c|}
\hline & Isomer & Sym & $\Delta E_{\mathrm{def}}$ & $\Delta E_{\text {int }}$ & $\Delta E_{\text {comp }}$ & $\Delta E_{\text {comp }}+\mathrm{ZPC}$ & $\Delta E$ \\
\hline \multirow{5}{*}{$\mathrm{F}^{-}+\mathrm{Ti}-\mathrm{T}_{8}$} & (a) Axial & $\mathrm{C}_{1}$ & 35.9 & -135.1 & -99.1 & -98.4 & $0.0[0.0]$ \\
\hline & (b) Equatorial & Cs & 55.6 & -150.6 & -95.0 & -94.8 & 3.6 \\
\hline & (c) Neighbor bridge & $\mathrm{C}_{1}$ & 56.3 & -151.4 & -95.1 & -93.7 & 4.7 \\
\hline & (d) Diagonal bridge & $\mathrm{C}_{2 \mathrm{v}}$ & 63.9 & -149.5 & -85.6 & -84.7 & 13.7 \\
\hline & (e) Endo & $\mathrm{C}_{1}$ & 23.2 & -125.3 & -102.1 & -101.6 & $-3.2[-7.6]$ \\
\hline
\end{tabular}

${ }^{\mathrm{a}}$ The values in italics are in square brackets.

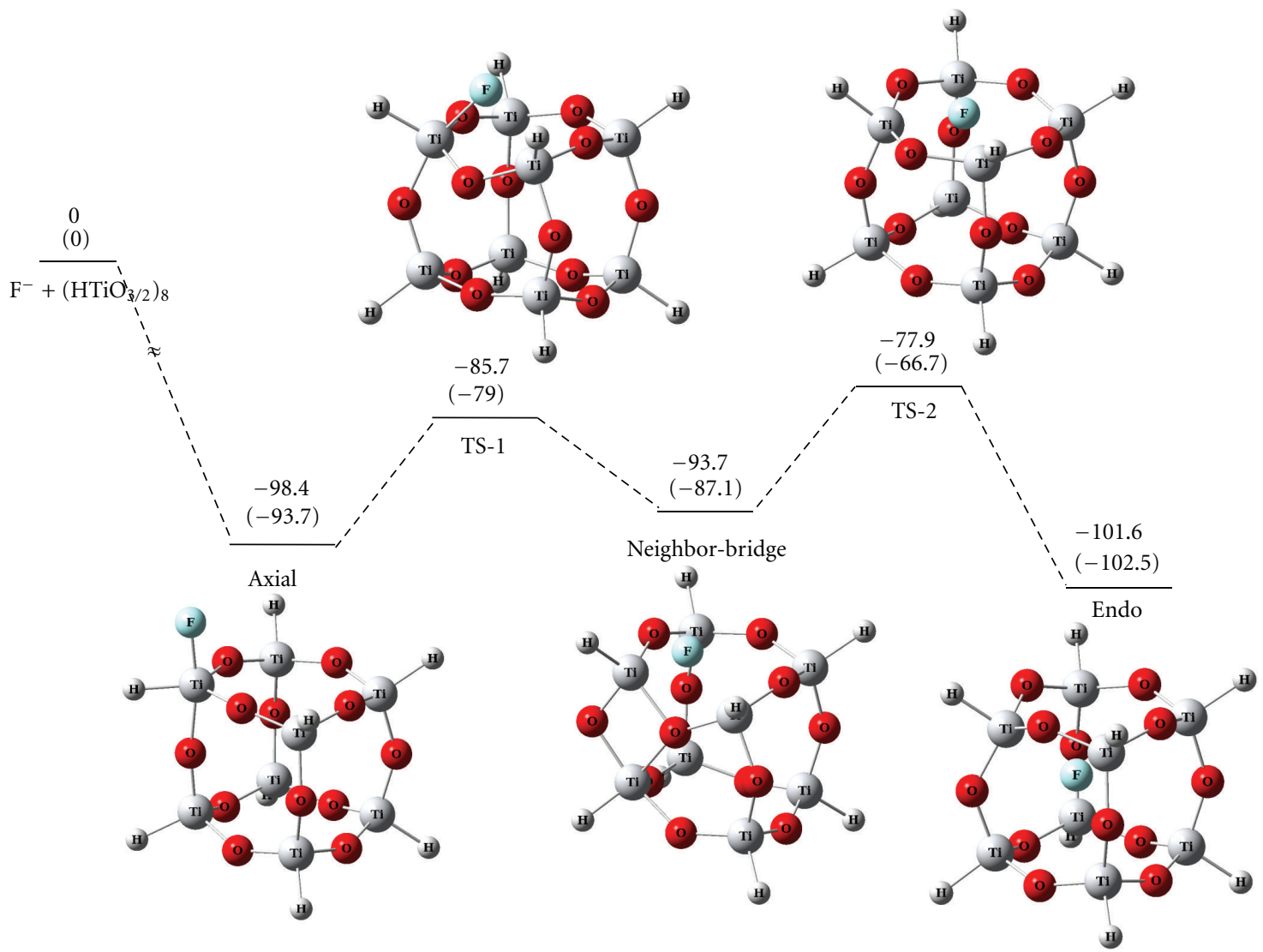

FIGURE 6: The potential energy surface $(\mathrm{kcal} / \mathrm{mol})$ of the insertion reaction of $\mathrm{F}^{-}$into Ti- $\mathrm{T}_{8}$ with the structures of some stationary points at the B3LYP/6-311+G(d)+ZPC and HF/6-311+G(d)+ZPC (in parentheses) levels.

changes. This is the same trend in the relation between $\mathrm{Li}^{+}$ and the heavier cations $\left(\mathrm{Na}^{+}\right.$and $\left.\mathrm{K}^{+}\right)$. That is, as the element of the group is lighter (smaller), it is able to interact with specific skeletal atoms in the cage, which brings about the larger deformation of the host cage.

On the other hand, the NBO charge of $\mathrm{Cl}^{-}$in the endohedral complex $\mathrm{Cl}^{-} @ \mathrm{Ti}-\mathrm{T}_{8}$ is -0.427 while that of $\mathrm{F}^{-}$in $\mathrm{F}^{-} @ \mathrm{Ti}-\mathrm{T}_{8}$ is -0.688 . This result suggests that the larger amount of minus charges is transferred from $\mathrm{Cl}^{-}$to the cage compared to the case of $\mathrm{F}^{-}$and the considerable electrostatic interaction between $\mathrm{Cl}^{-}$and the cage because of the large ionic radius even at the center of the cage.

The last topic of this section is the reaction mechanisms of the encapsulation of the halogen anions into $\mathrm{Ti}_{-} \mathrm{T}_{8}$. The potential energy surface of $\mathrm{F}^{-}$and $\mathrm{Cl}^{-}$is displayed in Figures 6 and 7, respectively. In both cases, the formation reaction of the exohedral complex (axial) is largely exothermic in energy. However, the following process is one-step reaction for $\mathrm{Cl}^{-}$while two-step reaction for $\mathrm{F}^{-}$because the "neighbor-bridge" structure exists between the exohedral and endohedral complexes for the latter as displayed in Figure 6. The "neighbor-bridge" complex has a diamondshaped $\mathrm{Ti}_{2} \mathrm{O}_{2}$ part in the strained structure. From the complex to the second TS (TS-2), the $\mathrm{F}^{-}$falls down into the cage with pushing out the oxygen of the flexible titanoxane ( $\mathrm{Ti}-$ $\mathrm{O}-\mathrm{Ti}$ ) bond to outside of the cage. As a result, the rhombus $\mathrm{Ti}_{2} \mathrm{O}_{2}$ structure is broken down and the energy needed for the motion brings about the second energy barrier of 


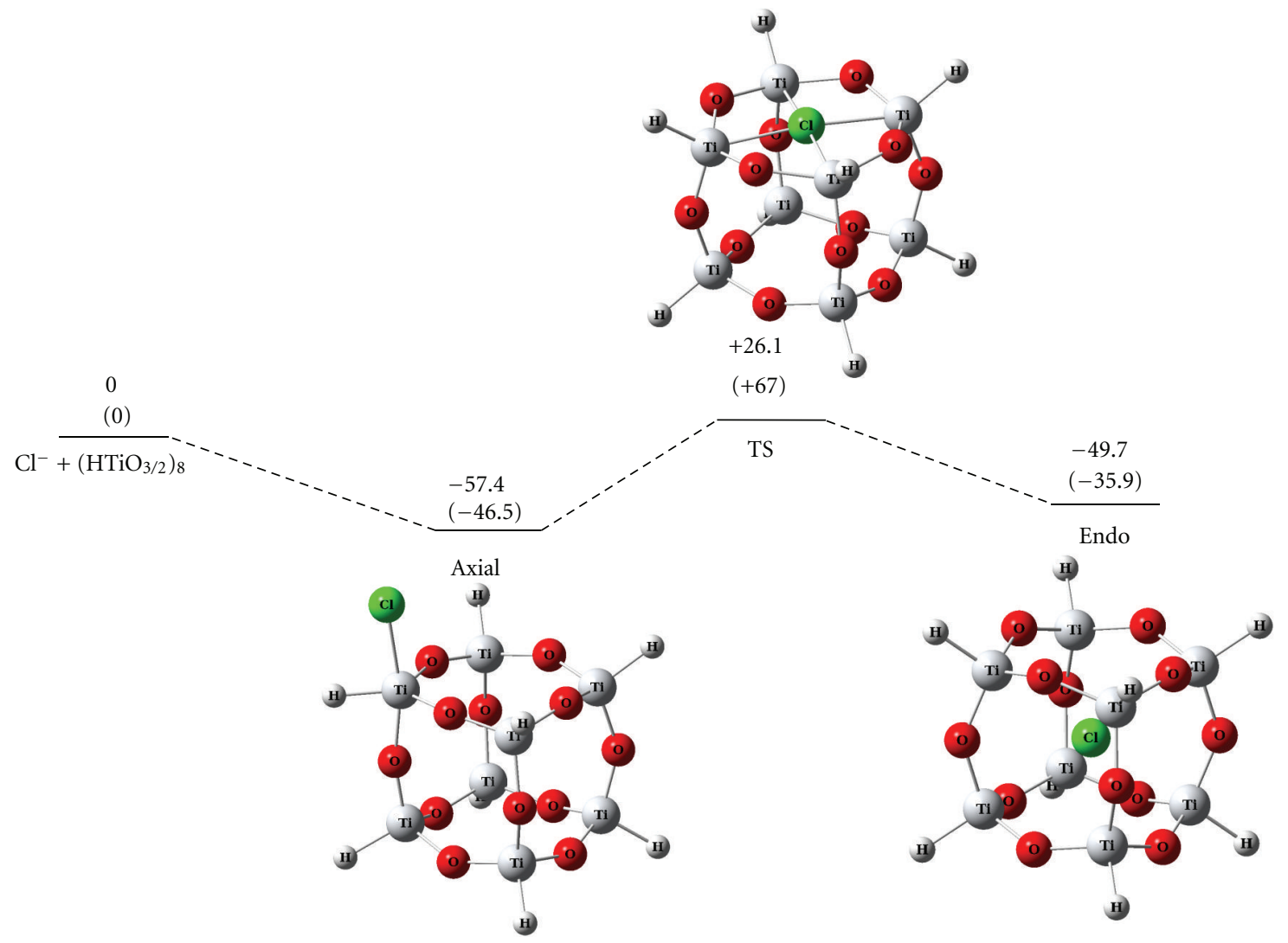

Figure 7: The potential energy surface $(\mathrm{kcal} / \mathrm{mol})$ of the insertion reaction of $\mathrm{Cl}^{-}$into Ti- $\mathrm{T}_{8}$ with the structures of the exohedral (Axial) and endohedral (Endo) complexes and the transition state (TS) connecting them at the B3LYP/6-311+G(d) $+\mathrm{ZPC}$ and HF/6-311+G(d) $+\mathrm{ZPC}$ (in parentheses) levels.

the reaction. All stationary points are lower than the reactants in energy. Therefore, the encapsulation of $\mathrm{F}^{-}$into $\mathrm{Ti}^{-} \mathrm{T}_{8}$ is predicted to take place rather easily. In fact, the absolute value of the $\Delta E_{\text {comp }}(-102.1 \mathrm{kcal} / \mathrm{mol})$ of the endohedral complex of $\mathrm{F}^{-}$and $\mathrm{Ti}-\mathrm{T}_{8}$ is largest among all species investigated in this study. In the silicon analogue, $\mathrm{F}^{-} @ \mathrm{~T}_{8}$ has already been observed experimentally so the Ti analogue may also be observed in near future.

For the encapsulation of $\mathrm{Cl}^{-}$, the anion inserts from the center of the $\mathrm{D}_{4}$ face as indicated from the TS structure in Figure 7. For the silicon analogue, $\mathrm{Cl}^{-} @ \mathrm{~T}_{8}$, the siloxane bond seems to be partially broken in the transition-state structure of the insertion and it could not keep the highly symmetric structure probably because of the smaller size of the cage [9]. As Figure 7 shows, the transition state "TS" for the insertion of $\mathrm{Cl}^{-}$into Ti- $\mathrm{T}_{8}$ is higher than the reactants in energy, which is different with the $\mathrm{F}^{-}$case but rather resembles to the rare gas elements and $\mathrm{Na}^{+}$and $\mathrm{K}^{+}$except for the fact that the endohedral complex is lower than the reactants.

3.5. Comparison with POSS. Finally, we compare the present results for the insertion reactions with those of the $\mathrm{Si}$ analogues $\left(\mathrm{T}_{8}\right)$ in order to clarify the characteristics of the Ti compounds. As already mentioned frequently, the same reaction of $\mathrm{T}_{8}$ has been investigated comprehensively by Park et al. [9] and the results are referred to in the preceding sections. Therefore, we just mention here the comparison of energetics of the reaction of $\mathrm{Ti}^{-} \mathrm{T}_{8}$ and $\mathrm{T}_{8}$ at the same level of theory in Table 7.

The trend of the binding energy $\left(\Delta E_{\text {comp }}\right)$, relative energies of the complexes, and the transition structures on the potential energy surface are similar for both compounds. The $\Delta E_{\text {comp }}$ of the exohedral complex of all elements except for $\mathrm{Ar}$ is minus, suggesting that these complexes are easily formed energetically. In addition, as the element becomes heavy, the relative stability of the transition state and endohedral complex becomes small probably because of their steric repulsion. Furthermore, the steric repulsion may explain that their relative energies are always larger in $\mathrm{T}_{8}$ than in $\mathrm{Ti}^{-} \mathrm{T}_{8}$ as the size of the cage of the former is smaller. Only one exception is the endohedral complex of $\mathrm{F}^{-} @ \mathrm{~T}_{8}$. The remarkable stability may be the reason why the complex has been observed experimentally. Also, the endohedral complex (endo) of $\mathrm{F}^{-} @ \mathrm{Ti}-\mathrm{T}_{8}$ is more stable than the exohedral (axial) complex though the relative stability is smaller than the $\mathrm{Si}$ analogue.

Furthermore, we should note that the considerably small release energy of the endohedral complex between $\mathrm{Li}^{+}$and $\mathrm{Ti}^{-} \mathrm{T}_{8}, \mathrm{Li}^{+} @ \mathrm{Ti}-\mathrm{T}_{8}$. This is the same trend as the corresponding silicon complex. As already noted, therefore, the inclusion complex of $\mathrm{Li}^{+}$and $\mathrm{Ti}^{-} \mathrm{T}_{8}$ may be hardly observed experimentally. 
TABle 7: The energetics $(\mathrm{kcal} / \mathrm{mol})$ of the encapsulation of $\mathrm{X}\left(\mathrm{X}=\mathrm{He}, \mathrm{Ne}, \mathrm{Ar} \mathrm{Li}^{+}, \mathrm{Na}^{+}, \mathrm{K}^{+}, \mathrm{F}^{-}\right.$, and $\left.\mathrm{Cl}^{-}\right)$into A-T $(\mathrm{A}=\mathrm{Si}$ and $\mathrm{Ti})$ at the $\mathrm{B} 3 \mathrm{LYP} / 6-311+\mathrm{G}(\mathrm{d})+\mathrm{ZPC}$ and MP2/6-311+G(d) $)^{\mathrm{a}}$ levels on the B3LYP/6-311+G(d) optimized geometries.

\begin{tabular}{|c|c|c|c|c|c|c|}
\hline \multirow{2}{*}{$\mathrm{X}$} & \multirow{2}{*}{$\begin{array}{c}\mathrm{A}-\mathrm{T}_{8} \\
\mathrm{~A}\end{array}$} & \multirow{2}{*}{$\Delta E_{\text {comp }}$ of exo } & \multicolumn{3}{|c|}{ Relative energy } & \multirow{2}{*}{ Release energy } \\
\hline & & & Exo & TS & Endo & \\
\hline \multirow{2}{*}{$\mathrm{He}$} & $\mathrm{Ti}$ & -0.1 & 0.0 & 31.2 & 7.6 & 23.6 \\
\hline & $\mathrm{Si}$ & -0.1 & 0.0 & 54.3 & 13.2 & 41.1 \\
\hline \multirow{2}{*}{$\mathrm{Ne}$} & $\mathrm{Ti}$ & -0.2 & 0.0 & 58.3 & 11.6 & 46.7 \\
\hline & $\mathrm{Si}$ & -0.1 & 0.0 & 109.5 & 24.1 & 85.4 \\
\hline \multirow{2}{*}{$\mathrm{Ar}$} & $\mathrm{Ti}$ & 0.0 & 0.0 & 145.2 & 46.0 & 99.2 \\
\hline & $\mathrm{Si}$ & 0.0 & 0.0 & 252.9 & 95.9 & 157.0 \\
\hline \multirow{2}{*}{$\mathrm{Li}^{+}$} & $\mathrm{Ti}$ & -38.1 & 0.0 & 27.8 & 25.8 & 2.0 \\
\hline & $\mathrm{Si}$ & -46.3 & 0.0 & 35.0 & 28.0 & 7.0 \\
\hline \multirow{2}{*}{$\mathrm{Na}^{+}$} & $\mathrm{Ti}$ & -21.6 & 0.0 & 60.7 & 31.7 & 29.0 \\
\hline & $\mathrm{Si}$ & -29.3 & 0.0 & 107.2 & 40.3 & 66.9 \\
\hline \multirow{2}{*}{$\mathrm{K}^{+}$} & $\mathrm{Ti}$ & -11.8 & 0.0 & 150.9 & 53.6 & 97.3 \\
\hline & $\mathrm{Si}$ & -17.7 & 0.0 & 237.1 & 85.8 & 151.3 \\
\hline \multirow{2}{*}{$\mathrm{F}^{-}$} & $\mathrm{Ti}$ & -98.4 & $0.0(0.0)$ & $12.7 / 20.5$ & $-3.2(-7.6)$ & 23.7 \\
\hline & $\mathrm{Si}$ & -58.6 & 0.0 & 65.9 & -13.2 & 79.1 \\
\hline \multirow{2}{*}{$\mathrm{Cl}^{-}$} & $\mathrm{Ti}$ & -57.4 & 0.0 & 83.5 & 7.7 & 75.8 \\
\hline & $\mathrm{Si}$ & -14.3 & 0.0 & 90.6 & 42.1 & 48.5 \\
\hline
\end{tabular}

${ }^{\mathrm{a}}$ The values are in parentheses.

\section{Concluding Remarks}

In the present work, the insertion reaction of various guest species such as rare gas, cations of the group 1, and anions of the group 17 elements, into the $\mathrm{Ti}$ analogue of $\mathrm{T}_{8}, \mathrm{Ti}^{-\mathrm{T}_{8}}$, has been investigated in comparison with the case of the $\mathrm{Si}$ analogue.

For rare gas elements, the mechanism of the insertion is the same as that of the $\mathrm{Si}$ analogue, $\mathrm{T}_{8}$; (1) formation of the exohedral complex where the atom is above the center of a $\mathrm{D}_{4}\left((\mathrm{HTiO})_{4}\right)$ face, $(2)$ interaction from the center of a $\mathrm{D}_{4}$ in the transition-state structure, and (3) formation of the endohedral complex with the atom in the center of the cage. The interaction with the host is rather small for all cases, and the energy for the encapsulation (energy barrier for the isomerization of exohedral to endohedral complexes) becomes large as the element becomes heavy.

On the other hand, for the cations of the group 1 elements, the reaction mechanism between $\mathrm{Li}^{+}$and the heavier elements $\left(\mathrm{Na}^{+}\right.$and $\left.\mathrm{K}^{+}\right)$is different. The latter group is rather similar to the rare gas elements in the geometries of the complexes and transition state, but $\mathrm{Li}^{+}$is found to interact with specific skeletal oxygen atoms and form two types of structures in both complexes as a result. Binding energy of all the complexes between $\mathrm{Li}^{+}$and $\mathrm{Ti}-\mathrm{T}_{8}$ is largely minus, suggesting that the complex of the cation and $\mathrm{Ti}^{-} \mathrm{T}_{8}$ is energetically more stable than the corresponding complex between rare gas elements and $\mathrm{Ti}-\mathrm{T}_{8}$. Furthermore, $\mathrm{Li}^{+}$interacts with the skeletal oxygen strongly in the exohedral complexes and the transition state for the encapsulation, which seems to make important contribution for their stability. As a result, the final product of the reaction, an endohedral complex, $\mathrm{Li}^{+} @ \mathrm{Ti}-\mathrm{T}_{8}$, is found to be kinetically unstable so only the exohedral complex may be existable.
Finally, for the anionic species of the group 17 elements, the behavior of $\mathrm{F}^{-}$is considerably unique. Several kinds of complexes are located for the reaction between $\mathrm{F}^{-}$and $\mathrm{Ti}-$ $\mathrm{T}_{8}$, while two types (exohedral and endohedral) of complexes are located for the case of $\mathrm{Cl}^{-}$. It may be worth to note that especially the position of $\mathrm{a} \mathrm{F}^{-}$is not the center of the cage in the endohedral complex but it takes the quasitriangular bipyramidal conformation at a corner of the cage. This is in sharp contrast with the fact that $\mathrm{F}^{-}$is in the center of the cage in the corresponding complex of the Si analogue, $\mathrm{F}^{-} @ \mathrm{~T}_{8}$. The same thing was also seen in the endohedral complex of $\mathrm{F}^{-} @ \mathrm{Ti}-\mathrm{T}_{10}$, while $\mathrm{F}^{-}$was found to be the center of the cage in smaller $\mathrm{Ti}_{-} \mathrm{T}_{6}$. Therefore, the larger room of the $\mathrm{Ti}^{-} \mathrm{T}_{8}$ and Ti- $\mathrm{T}_{10}$ compared to the corresponding Si cages as well as the strong electrostatic interaction between $\mathrm{F}^{-}$and $\mathrm{Ti}$ atom may allow the unique structure. Furthermore, this prediction can explain the observation in $\mathrm{F}^{-} @ S i-\mathrm{T}_{10}$ and $\mathrm{F}^{-} @ S i-\mathrm{T}_{12}$ where $\mathrm{F}^{-}$is bound at the corner of the cage $[11,12]$.

In summary, for the present encapsulation reaction of Ti$\mathrm{T}_{8}$, we found quite a few similar properties with those of the silicon analogue, $\mathrm{T}_{8}$, in spite of the considerable difference in the nature of the skeletal bond and size of the cage. This means the reaction is mainly affected by the size of the host cage and not the skeletal elements. However, for the reaction of Ti-POSS, the strong interaction between the ionic species and a part of the skeletal atoms is still expected to play an important role. As an extension of the present study, therefore, an investigation of the intra-molecular catalytic reaction inside Ti-POSS is now in progress.

The discussion for the cage effect in the $\mathrm{F}^{-} @ \mathrm{Ti}^{-} \mathrm{T}_{n}(n=8$ and 10) (Figures S1-S3 and Tables S1 and S2), see the supplementary material available online at doi: 10.1155/2012/ 391325. 


\section{Acknowledgment}

This work was partly supported by the "Element Innovation" Project by Ministry of Education, Culture, Sports, Science and Technology in Japan.

\section{References}

[1] M. G. Voronkov and V. L. Lavrent'yev, “ Polyhedral oligosilsesquioxanes and their homo derivatives," Topics in Current Chemistry, vol. 102, pp. 199-236, 1982.

[2] F. J. Feher, D. A. Newman, and J. F. Walzer, "Silsesquioxanes as models for silica surfaces," Journal of the American Chemical Society, vol. 111, no. 5, pp. 1741-1748, 1989.

[3] R. H. Baney, M. Itoh, A. Sakakibara, and T. Suzuki, "Silsesquioxanes," Chemical Reviews, vol. 95, no. 5, pp. 1409-1430, 1995.

[4] F. J. Feher and T. A. Budzichowski, "Silasesquioxanes as ligands in inorganic and organometallic chemistry," Polyhedron, vol. 14, no. 22, pp. 3239-3253, 1995.

[5] B. Tejerina and M. S. Gordon, "Insertion mechanism of $\mathrm{N}_{2}$ and $\mathrm{O}_{2}$ into $\mathrm{T}_{n}(n=8,10,12)$-silsesquioxane framework," Journal of Physical Chemistry B, vol. 106, no. 45, pp. 11764 11770, 2002.

[6] L. A. Villaescusa, P. Lightfoot, and R. E. Morris, "Synthesis and structure of fluoride-containing $\mathrm{GeO}_{2}$ analogues of zeolite double four-ring building units," Chemical Communications, no. 19, pp. 2220-2221, 2002.

[7] A. R. Bassindale, M. Pourny, P. G. Taylor, M. B. Hursthouse, and M. E. Light, "Fluoride-Ion encapsulation within a silsesquioxane cage," Angewandte Chemie, vol. 42, no. 30, pp. 3488 3490, 2003.

[8] A. R. Bassindale, D. J. Parker, M. Pourny, P. G. Taylor, P. N. Horton, and M. B. Hursthouse, "Fluoride ion entrapment in octasilsesquioxane cages as models for ion entrapment in zeolites. Further examples, X-ray crystal structure studies, and investigations into how and why they may be formed," Organometallics, vol. 23, no. 19, pp. 4400-4405, 2004.

[9] S. S. Park, C. Xiao, F. Hagelberg, D. Hossain, C. U. Pittman Jr., and S. Saebo, "Endohedral and exohedral complexes of polyhedral double four-membered-ring (D4R) units with atomic and ionic impurities," Journal of Physical Chemistry A, vol. 108, no. 51, pp. 11260-11272, 2004.

[10] G. Satre, A. Pulido, and A. Corma, "Pentacoordinated germanium in AST zeolite synthesised in fluoride media. A ${ }^{19} \mathrm{~F}$ NMR validated computational study " Chemical Communications, vol. 2005, pp. 2357-2359, 2005.

[11] M. Pach, R. M. Macrae, and I. Carmichael, "Hydrogen and deuterium atoms in octasilsesquioxanes: experimental and computational studies," Journal of the American Chemical Society, vol. 128, no. 18, pp. 6111-6125, 2006.

[12] J. A. Tossell, "Calculation of ${ }^{19} \mathrm{~F}$ and ${ }^{29} \mathrm{Si}$ NMR shifts and stabilities of $\mathrm{F}^{-}$encapsulating silsesquioxanes," The Journal of Physical Chemistry C, vol. 111, pp. 3584-3590, 2007.

[13] D. Hossain, C. U. Pittman Jr., S. Saebo, and F. Hagelberg, "Structures, stabilities, and electronic properties of endoAnd exohedral complexes of T10-polyhedral oligomeric silsesquioxane cages," Journal of Physical Chemistry C, vol. 111, no. 17, pp. 6199-6206, 2007.

[14] S. E. Anderson, D. J. Bodzin, T. S. Haddad et al., "Structural investigation of encapsulated fluoride in polyhedral oligomeric silsesquioxane cages using ion mobility mass spectrometry and molecular mechanics," Chemistry of Materials, vol. 20, no. 13, pp. 4299-4309, 2008.
[15] D. Hossain, C. U. Pittman Jr., F. Hagelberg, and S. Saebo, "Endohedral and exohedral complexes of T8-polyhedral oligomeric silsesquioxane (POSS) with transition metal atoms and ions," Journal of Physical Chemistry C, vol. 112, no. 41, pp. 16070-16077, 2008.

[16] D. Hossain, S. R. Gwaltney, C. U. Pittman, and S. Saebo, "Insertion of transition metal atoms and ions into the nanoscale dodecahedral silsesquioxane (T12-POSS) cage: structures, stabilities and electronic properties," Chemical Physics Letters, vol. 467, no. 4-6, pp. 348-353, 2009.

[17] A. R. Geoge and C. R. A. Catlow, "An investigation into the effects of ion incorporation on the electronic structure of silicate fragments via ab initio computational techniques," Chemical Physics Letters, vol. 247, no. 4-6, pp. 408-417, 1995.

[18] T. Kudo, M. Akasaka, and M. S. Gordon, "Ab initio molecular orbital study of the insertion of $\mathrm{H}_{2}$ into POSS compounds," Theoretical Chemistry Accounts, vol. 120, no. 1-3, pp. 155-166, 2008.

[19] T. Kudo, "Ab initio molecular orbital study of the insertion of $\mathrm{H} 2$ into poss compounds 2: the substituent effect and larger cages," Journal of Physical Chemistry A, vol. 113, no. 44, pp. 12311-12321, 2009.

[20] C. McCusker, J. B. Carroll, and V. M. Rotello, "Cationic polyhedral oligomeric silsesquioxane (POSS) units as carriers for drug delivery processes," Chemical Communications, vol. 8, pp. 996-998, 2005.

[21] H. Yuan, K. Luo, Y. Lai et al., "A novel poly(l-glutamic acid) dendrimer based drug delivery system with both $\mathrm{pH}$-sensitive and targeting functions," Molecular Pharmaceutics, vol. 7, no. 4, pp. 953-962, 2010.

[22] T. Kudo, T. Taketsugu, and M. S. Gordon, "Ab initio molecular dynamics study of $\mathrm{H}_{2}$ formation inside POSS compounds," The Journal of Physical Chemistry A, vol. 115, pp. 2679-2791, 2011.

[23] A. Voigt, R. Murugavel, V. Chandrasekhar et al., "Facile and rational route for high-yield synthesis of titanasiloxanes from aminosilanetriols," Organometallics, vol. 15, no. 6, pp. 16101613, 1996.

[24] M. Crocker, R. H. M. Herold, A. G. Orpen, and M. T. A. Overgaag, "Synthesis and characterisation of titanium silasesquioxane complexes: soluble models for the active site in titanium silicate epoxidation catalysts," Journal of the Chemical Society, Dalton Transactions, no. 21, pp. 3791-3804, 1999.

[25] R. Murugavel, P. Davis, and V. S. Shete, "Reactivity studies, structural characterization, and thermolysis of cubic titanosiloxanes: precursors to titanosilicate materials which catalyze olefin epoxidation," Inorganic Chemistry, vol. 42, no. 15 , pp. 4696-4706, 2003.

[26] K. Wada, N. Itayama, N. Watanabe, M. Bundo, T. Kondo, and T. A. Mitsudo, "Synthesis and catalytic activity of group 4 metallocene containing silsesquioxanes bearing functionalized silyl groups," Organometallics, vol. 23, no. 24, pp. 5824-5832, 2004.

[27] T. Kudo and M. S. Gordon, "Structures and stabilities of titanium silsesquioxanes," The Journal of Physical Chemistry A, vol. 105, no. 50, pp. 11276-11294, 2001.

[28] T. Kudo and M. S. Gordon, "Ab initio study of the catalytic reactivity of titanosilsesquioxanes and titanosiloxanes," Journal of Physical Chemistry A, vol. 107, no. 41, pp. 8756-8762, 2003.

[29] T. Kudo, M. Akasaka, and M. S. Gordon, "Ab initio molecular orbital study on the $\mathrm{Ge}^{-}, \mathrm{Sn}^{-}, \mathrm{Zr}^{-}$and $\mathrm{Si} / \mathrm{Ge}$-mixed silsesquioxanes," The Journal of Physical Chemistry A, vol. 112, no. 21, pp. 4836-4843, 2008. 
[30] A. J. M. de Man and J. Sauer, "Coordination, structure, and vibrational spectra of titanium in silicates and zeolites in comparison with related molecules. An ab initio study," The Journal of Physical Chemistry, vol. 100, no. 12, pp. 5025-5034, 1996.

[31] P. E. Sinclair and C. R. A. Catlow, "Quantum chemical study of the mechanism of partial oxidation reactivity in titanosilicate catalysts: active site formation, oxygen transfer, and catalyst deactivation," The Journal of Physical Chemistry B, vol. 103, no. 7, pp. 1084-1095, 1999.

[32] A. D. Becke, "Density-functional thermochemistry. III. The role of exact exchange," The Journal of Chemical Physics, vol. 98, no. 7, pp. 5648-5652, 1993.

[33] M. M. Francl, W. J. Pietro, W. J. Hehre et al., "Self-consistent molecular orbital methods. XXIII. A polarization-type basis set for second-row elements," The Journal of Chemical Physics, vol. 77, no. 7, pp. 3654-3665, 1982.

[34] T. Clark, J. Chandrasekhar, G. W. Spitznagel, and P. V. R. Schleyer, "Efficient diffuse function-augmented basis sets for anion calculations. III. The $3-21+\mathrm{G}$ basis set for first-row elements, Li-F," Journal of Computational Chemistry, vol. 4, pp. 294-301, 1983.

[35] M. J. Frish, J. A. Pople, and J. S. Binkley, "Self-consistent molecular orbital methods 25. Supplementary functions for Gaussian basis sets," The Journal of Chemical Physics, vol. 80, pp. 3265-3269, 1984.

[36] J. A. Pople, R. Seeger, and R. Krishnann, "A semi-empirical MO theory for ionization potentials and electron affinities," International Journal of Quantum Chemistry, vol. 11, pp. 149163, 1977.

[37] M. J. Frisch, G. W. Trucks, H. B. Schlegel et al., Gaussian 03, Revision C. 02, Gaussian, Wallingford, Conn, USA, 2004.

[38] M. W. Schmidt, K. K. Baldridge, J. A. Boatz et al., "General atomic and molecular electronic structure system," Journal of Computational Chemistryvol, vol. 14, pp. 1347-1363, 1993.

[39] M. S. Gordon and M. W. Schmidt, "Advances in electronic structure theory: GAMESS a decade later," in Theory and Applications of Computational Chemistry, C. E. Dykstra, G. Frenking, K. S. Kim, and G. E. Scuseria, Eds., chapter 41, Elsevier, San Diego, Calif, USA, 2005.

[40] J. P. Foster and F. Weinhold, "Natural hybrid orbitals," Journal of the American Chemical Society, vol. 102, no. 24, pp. 72117218,1980 . 

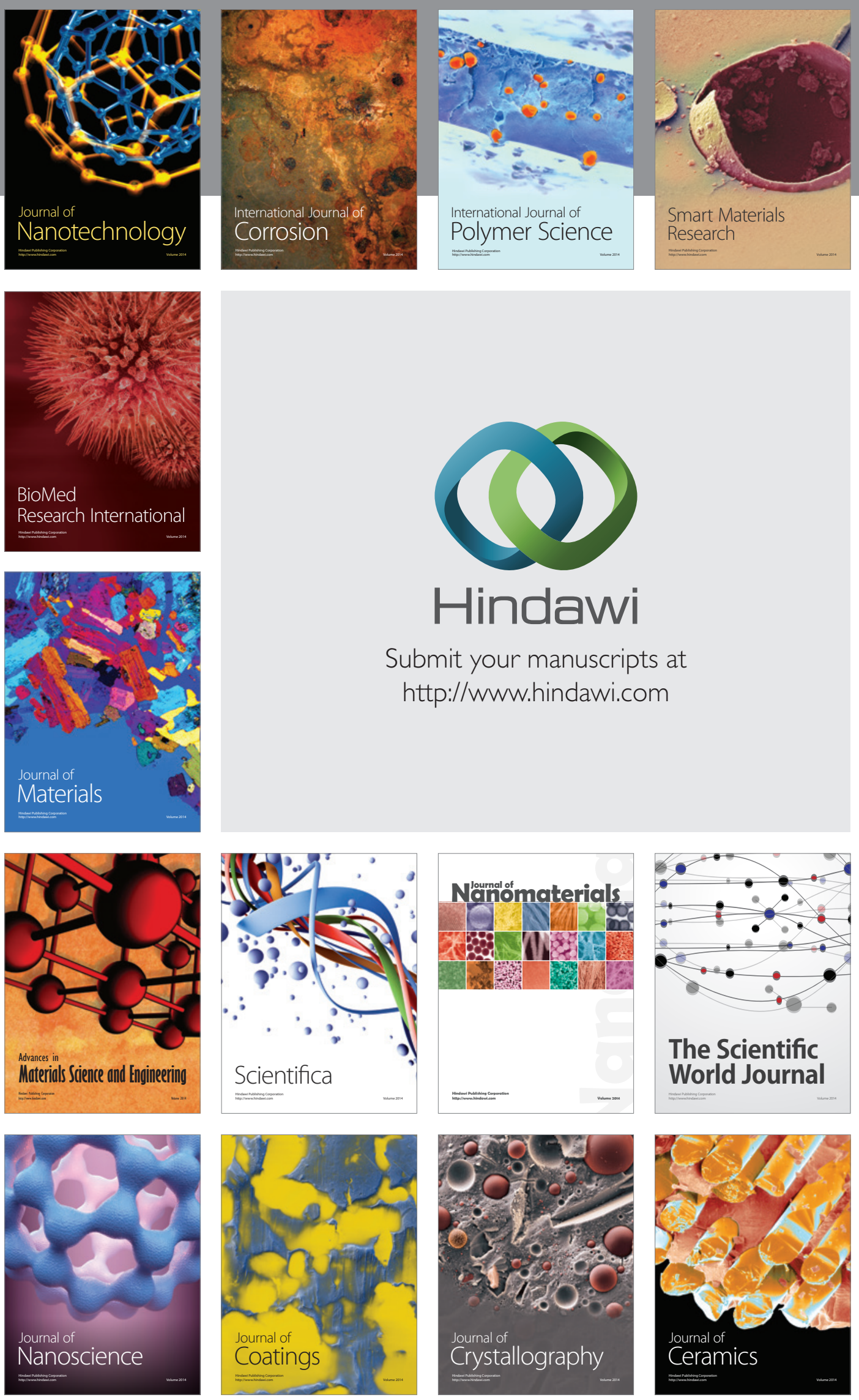

The Scientific World Journal

Submit your manuscripts at

http://www.hindawi.com

\section{World Journal}

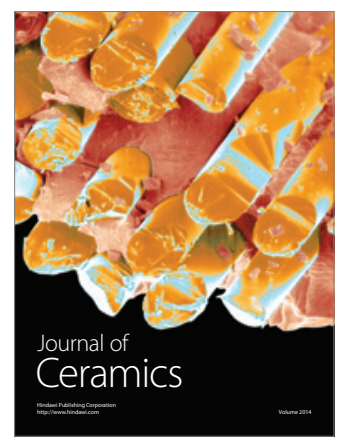

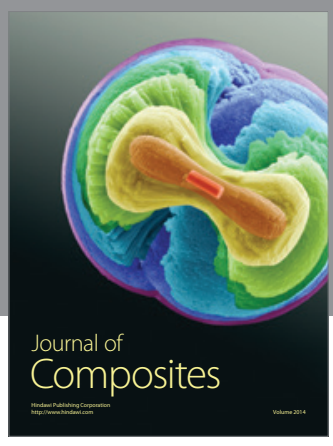
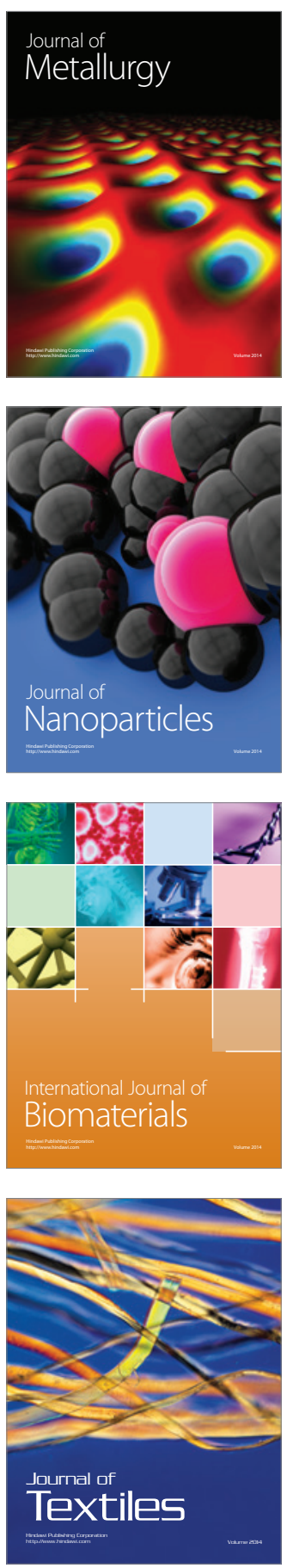